\title{
Title \\ ASSESSING THE APPLICABILITY OF PASSIVE COOLING AND HEATING TECHNIQUES THROUGH CLIMATE FACTORS: AN OVERVIEW
}

\section{Authors}

Tejero-González, Ana'; García-Ibáñez, Paola ${ }^{1}$; Andrés-Chicote, Manuel ${ }^{1}$; Velasco-Gómez, Eloy ${ }^{1}$; Rey-Martínez, Francisco Javier ${ }^{1}$.

${ }^{1}$ Department of Energy and Fluidmechanics, University of Valladolid, Paseo del Cauce № 59 47011, Valladolid, Spain.

\section{Corresponding Author:}

Tejero-González, Ana e-mail: anatej@eii.uva.es

Tel.: (+34)983423684

Fax: (+34)983423363

\begin{abstract}
A review on climate parameters affecting applicability of passive and low energy heating and cooling techniques is presented. The study has been developed from existing research work results, and aims to serve as a first-stage assessment tool of the viability of these solutions at a particular location, depending on outdoor conditions to be faced. This contribution starts with a justification of comprehensive climate analysis as the first step to evaluate whether a specific passive or low energy solution would be efficient, or on the contrary, it would incur in higher energy consumption. Comfort requirements indoors as well as building typology and use are then briefly tackled as they would determine actual applicability. It continues gathering the weather variables affecting passive solar, natural ventilation, free cooling and evaporative cooling technologies. Key climatic information is provided for the city of Valladolid (Spain), as an example. Finally it ends with an overview of existing tools for representing climate information in bioclimatic design. Thus, the main target of this paper is to serve as a guide for an adequate preselection of the optimal passive energy solutions in buildings at a specific site, from existing research on climate analysis.
\end{abstract}

\section{Keywords}

Energy efficiency; Climate assessment; Solar passive; Natural ventilation; Free-cooling; Evaporative cooling.

\footnotetext{
Abbreviations

DBT: Dry Bulb Temperature $\mathrm{RH}$ : Relative Humidity WBT: Wet Bulb Temperature DPT: Dew Point Temperature WBD: Wet Bulb Depression DEC: Direct Evaporative Cooling IEC: Indirect Evaporative Cooling
} 


\section{Introduction}

The current increase in primary energy consumption is widely recognized to be unsustainable. Consequently, actions are being driven in order to either avoid the misuse of resources or reduce the energy demand. Buildings are targeted as they constitute one of the most potential sectors in this sense. Particularly, they accounted for $40 \%$ of the total energy consumption in Europe in 2010 [1], percentage that has been increasing by around 1\% per year since 1990 [2]. The largest contributors to this high and rising energy consumption are Heating, Ventilation and Air Conditioning (HVAC) systems.[3]. Moreover, the situation is worsened by the continuous development that leads to a rise in urban population [4], which spends more time indoors (85$90 \%$ on average) [5]. Provided that high quality of life is expected, consequent indoor comfort conditions result into a foreseeable increase of the percentage of energy consumed by HVAC systems.

Besides, it is estimated that most of the energy consumed in buildings could be saved. Consequently, legislation as the Energy Performance of Buildings Directive in Europe [1] is being introduced, and is constantly being revised to enhance energy savings within the sector. In this context, solutions to reduce energy consumption from its origin (demand) arises as the first step to be considered, before implementing further procedures proposed by current legislation. Having this into concern, climate analysis is a key point, due to the intrinsic relation between climate and energy demand for thermal comfort. It also highlights the importance of climate change on future energy trends [6].

\subsection{Evaluation of passive techniques applicability}

Passive techniques stand out among the possible solutions to reduce energy demand. They actually represent the oldest way to reduce heating and cooling loads, and nowadays are enhanced for having repeatedly proved to be sustainable alternatives to current conventional techniques [7, 8]. However, their effectiveness depends directly on site conditions, varying not only from season to season but also along the daytime. Consequently, not every alternative might be a solution for one given location, but local climatic conditions must be carefully considered.

Thereby, to evaluate applicability of any passive solution a comprehensive analysis of the heating and cooling demand is needed. This requires a thorough study of the climate, as well as the provision of detailed information about the target building and about the indoor comfort expectations [9]. The evaluation of these three issues (climate, building and indoor conditions) constitutes an exhaustive study to determine whether the implementation of any technique is feasible or not at a particular location according to its specific conditions.

If we aim at simplifying the analysis, we might try to omit any of these three aspects as a first approach. Thermal comfort requirements are far from being a negligible factor on building energy consumption, as less strict conditions lead to lower energy demand [10]. Indeed, energy savings from $32 \%$ to $73 \%$ depending on climate conditions have been achieved in HVAC 
systems by loosening setpoint restrictions [11]. For their part, building characteristics (envelope, building use, etc.) directly determine wall conduction and internal heat loads. In fact, it has been calculated that around one third of the total cooling load in a building might be due to its envelope design, which is also closely related to the outdoor environment [12]. However, according to its direct and indirect influence, deep knowledge of climatic conditions is the principal requirement to perform a building design intended for the improvement of energy efficiency [13]. Moreover, it should be remarked that building characteristics are not easily modifiable once it is built. What is more, sometimes, implementation proposals of passive heating and cooling techniques are addressed in the early design stage, so no specific building can be considered. On the contrary, the aim at that point usually consists of refining possible building designs based on the application of viable passive techniques [9]. Therefore, a simplified analysis limited to climatic data could supply conclusive information on the feasibility of application of these passive heating and cooling strategies at a particular location.

In this respect, commercial environmental bioclimatic design tools are complex and not extensively used, which demonstrates that a simpler climate analysis tool for the initial design planning is necessary [13]. With this aim, analysis of local climatic conditions must be stated as the first step when estimating heating and cooling loads to analyse equipment viability and optimise systems sizing [12].

\subsection{Scope of the review}

The purpose of this review work is to compile existing results on the applicability and potential of selected passive and low-energy strategies, according only to climate operating conditions. Once the possibility of focusing the analysis on the climate has been justified in the first part of this introduction, Section 2 relates climate variables with the heating and cooling loads that these strategies must face. Then the importance of the reliability of climatic data is also highlighted.

Target passive and low-energy solutions have been selected for being mainly dependent of climate variables. To pursue the objective of studying their interest according to the climate, in Section 3 we identify specific climate factors studied in different research work for each proposed conditioning solution, together with those results concerning applicability ranges or degree of interest. This information is gathered into tables to provide a global overview. Subsection 3.1 describes how climate conditions need to be studied so that they can contribute to the adaptation of passive solar heating solutions during summer periods. Possibilities for using outdoor air as a heat sink through natural ventilation and free-cooling are then analyzed in Subsection 3.2. Particularly, it focuses on key values to be considered in free-cooling control. Besides, Subsection 3.3 addresses the examination of several evaporative cooling implementation options appropriate for different climate conditions.

In order to illustrate the discussion of the compiled results, a comparative analysis for various climates has been simultaneously introduced throughout Section 3. Climates have been selected taking into consideration only summer conditions. This is justified given that the interest 
of target passive techniques is highly dependent on their adaptability during summer periods (which is the case of passive solar heating) if not directly intended for cooling. Then, combinations of "temperate" and "hot" with "dry" and "humid" summers are considered. "Cold" summers are disregarded in the study for being undoubtedly interesting for free cooling applications or summer adaptability of passive solar heating. According to the Köppen-Geiger climate classification, the following examples have been chosen [14], [15]: Valladolid (Spain) for temperate and dry summers ("Csb": Temperate climate with dry, warm summers); Las Vegas (US) for hot and dry summers ("Bwh": Arid, desert, hot climate); London (UK) for temperate, humid summers ("Cfb": Temperate climate without dry season, warm summer); and Sidney (Australia) for hot, humid summers ("Cfa": Temperate climate without dry season, hot summer). Finally, Section 4 of this the paper summarizes the existing methods to collect and present climatic data, aiming to serve to the decision-making process at the early steps of a building passive design.

Thereby it could be possible to approach the evaluation of the local applicability of a particular passive technique without further information on the building use or comfort conditions, by referring to existing research work.

\section{Heating and cooling demand due to the climate.}

Climate conditions can entrain the potential to reduce demand if the adequate passive strategy is followed. But at the same time, these conditions affect the heating and cooling demand that this strategy has to face. This makes the study of the energy savings introduced by passive systems an intricate study usually approached through dynamic building simulation. However, simplified approaches can be developed for a first rough evaluation. Campaniço et al [16] propose a performance indicator called "Climatic Cooling Potential" to estimate energy savings introduced by passive ventilation-dependent cooling techniques, only from climate data on a monthly basis. The various passive options studied are characterized by supply temperature achieved and corresponding airflow, through climatic hourly cooling potential.

Since the weather has such great impact on heating and cooling energy demand, it is possible to estimate loads through quite simple tools such as the Degree-Days (DD) or the Bin-method. Measuring the environmental conditions by the DD can also predict energy efficiency of a building. Tzikopoulos et al. [17] observed on Mediterranean bioclimatic buildings that energy efficiency decreased by $7 \%$ each 50 Degree-months, also affected about a $17 \%$ by the location of the building.

Furthermore, climate change scenarios are being studied to characterize how it affects the energy demand associated to the achievement of thermal comfort in indoor spaces [18, 19, 20]. Santamouris [21] demonstrates how temperatures are affected due to urban heat islands, and consequently how real operating conditions and final energy consumption for cooling can also differ.

However, outdoor conditions do not only affect air-conditioning demand. Actually, they also influence system's operation. Both comfort set-points and outdoor temperatures are essential 
for the Coefficients of Performance (COPs) of conventional compression cooling systems [22]. Consequently, this highlights the future effect of climate change scenarios in terms of HVAC equipment efficiency and applicability [23]. Yau and Pean [24] calculated that every $1^{\circ} \mathrm{C}$ temperature increase can reduce COP in a $2 \%$. On the other hand, Sobrinho and Tuna [25] proved that relative humidity also influences systems' COP when exceeding $65 \%$.

Then, beyond the impact of weather on systems' performance, final energy consumptions will differ from estimations due to reliability of climatic data, which become obsolete as climate changes [12]. This happens because hourly weather data is obtained from a Typical Meteorological Year (TMY), which is built collecting selected months from data of a number of past years. Hence, this available climate information, as obtained from historical data, only foresees probable occurrence of conditions. Nonetheless, errors between expected and measured energy consumptions might be minimized if the origin of data is validated, as studied by Radhi for Bahrain [26]. They obtained a difference of $14.5 \%$ between simulated results with actual measured data and old climatic information, whereas results obtained with more recent data only differed a $1.4 \%$. They justified their results on the continuous rising of typical outdoor temperature and irradiance levels together with decreasing wind velocities and humidity.

Consequently, countless research work has been developed concerning reliability of climatic data sources at different particular locations. These works seek improving the quality of data by either reviewing databases or estimating a new "non-real" typical year. Some recent examples study these effects in Thailand [27], China [28], Hong Kong [29], Nigeria [30] and other different climates [31]. Skeiker and Ghani [32] deepen into the selection criterion of a typical meteorological year, from typical meteorological months. Particularly, they developed a new software selection tool focusing on key meteorological parameters: $\mathrm{DBT}, \mathrm{RH}$, wind velocity and global solar radiation.

Despite all these efforts, meteorological data are sometimes incomplete and required information is not available. To overcome this, Guan et al. [33] study correlations among the main weather variables (solar irradiation, DBT, atmospheric pressure, $\mathrm{RH}$, and wind velocity) using the DBT as a reference, to render a method to estimate the missed information. They obtained strong direct correlations between DBT and solar irradiation, and also inverse correlations between this same parameter and $\mathrm{RH}$. These results are quite interesting for interpretation of passive techniques potential focusing the analysis on selected parameters. However, correlations between DBT and atmospheric pressure and wind speed are weaker and thus less useful for the case of study.

Nonetheless, when weather forecast is available, it is decidedly preferable to directly measure the real conditions at the specific site. Actually, energy efficiency is more probable to be improved through those analyses and control strategies based on real measured climatic variables, rather than through those ones resorting to TMY information [34].

Provided that available data are reliable, climatic parameters could be defined not only to characterize heating and cooling loads, but also to determine the feasibility of application and 
potential of different target passive techniques. Hereunder, relevant climatic parameters are gathered from results of research work developed on the reviewed passive solutions.

\section{Climatic parameters studied for passive and low-energy heating and cooling techniques}

Climate data provides information about a number of psychrometric variables of the ambient air, as well as solar and wind parameters. When evaluating the interest of any passive strategy for building conditioning at a given location, before having any knowledge on the particular building design, some among these variables can be of great utility.

Regarding heating applications, passive solutions focus on minimizing losses and maximizing gains. On the contrary, concerning cooling design the goals are both avoiding these gains and removing heat to the environment: to the air, water, ground or the sky [35], [8].

Psychrometric variables represent the capacity of some of the available environmental heat sinks to absorb such heat removal. These sinks are: the ambient air, used through ventilation strategies; and water, exploited through evaporative cooling processes. Moreover, wind information broadens the analysis of ventilation possibilities, as favorable winds enhance natural ventilation if considered for the future design of the building. On the other hand, solar parameters are useful for the evaluation of passive solar heating solutions as well as for shading designs to prevent solar heat gains during the cooling season. Nighttime radiant dissipation relies on sky temperature, but falls beyond the scope of this contribution for being excessive dependent on building characteristics. Finally, despite the fact that the ground stands among the possible environmental heat sinks, climate data usually do not provide information for a preliminary analysis in this sense, and consequently it also exceeds the purpose of this work.

When handling large amounts of climate data, a definition of parameters and analysis tools are needed to ease the characterization of the associated operating conditions throughout the year. Once these characteristic conditions for a particular location are determined, the interesting ones for implementing a certain passive solution can be identified among them. This paper here reviews the main climatic parameters considered to study the applicability and effectiveness of passive conditioning techniques and their consequent conclusions. To illustrate how to read and use this information, alternative representation of key parameters is given for the different climates chosen in subsection 1.2, according to the available TMY data for Valladolid [36] and the remaining climates studied [37]. 


\subsection{Passive solar heating and cooling}

Solar heating of indoor environments during winter periods is based on maximizing direct solar gains and storing the heat into the building thermal mass. There are various passive solar strategies involving either the building façade or roof, such as solar façades or Trombe walls. Solar facades designs favor the direct solar gains to heat the building during winter, or transform it into indoor air movement with cooling purposes. They can be opaque or translucid and are extensively reviewed by Quesada et al. [38], [39]. Their operation can be improved if ventilation through a double skin is permitted, broadening their application to hot-summer and cold-winter climates as studied by Zhou\&Chen [40]. Trombe walls basically consist of a massive wall that can store the heat from the radiation that goes through a glazing, an air layer in between, vents and dampers to modify its operating mode, but a number of different designs are reviewed by Saadatian et al [41].

However, although mainly intended for heating, these solutions rely on fixed equipment that cannot be removed during the summer period. Then, they must be designed to face also cooling demand, or, at least, not to harm indoor thermal comfort under such circumstances. Otherwise, their application would be limited to cold climates, due to overheating problems in mild and harsh conditions. Consequently, the study of these strategies for heating must be conceived together with their cooling applications. However, their efficiency when operating in summer mode is intrinsically related to the design and operation of its elements as well as by occupants's behavior and conditions indoors, as studied by Stazi et al for Trombe walls [42]. This adaptability lies on the possibility of operating either as insulation or ventilation systems, together with appropriate shading. To help achieving comfort through ventilation, they must benefit from solar gains to create stratification of indoor air temperature, which leads to air movement.

On the contrary, solar chimneys are particularly designed to enhance natural ventilation indoors in summer, by driving airflow inside through thermal buoyancy, optimized by solar radiation. To be effectively applied in winter, heated air is supplied indoors with the aid of a fan [43].

Although available radiation is the key factor concerning solar heating, existing research work in this field highlights further parameters other than solar data to evaluate solar cooling options:

Solar irradiation and solar path: Available radiation comprises basic information required for predicting heating potential and viability of ventilation strategies through stratification. Solar path (zenith and azimuth) is also needed for a proper shading design that also ensures effective lighting. It enables an accurate design of shading devices and direct solar gains according to local and seasonal requirements. Ralegaonkar\&Gupta [44] make a concise review in this sense within the context of passive solar architecture, referring to existing work developed on estimating solar irradiation available and the key parameters to be considered. 
However, surrounding elements might create undesired shading that limit viability of passive strategies, so they need to be considered together with the solar data of the location, especially in urban environments [45]. Moreover, shading control also must account for cloudiness in order to maximize diffuse radiation for lighting [46]. Consequently, extensive analysis of solar passive technologies expands from merely considering solar parameters, including, at least, cloud cover proportion; but this falls beyond the scope of the present paper.

Because solar cooling seeks enhancing natural ventilation, its effectiveness will depend not only on the received solar radiation but also on the outdoor air DBT and its temperature difference with the indoor environment (hereafter referred as 'DBT-Indoor temperature difference')

DBT-Indoor temperature difference: The interest of solar cooling in hot and humid climates lies in the inefficiency of simple stack ventilation due to low indoor/outdoor temperature difference. In such situations, the effect of solar radiation on the temperature increase is a feasible solution. Chungloo and Limmeechokchai [47], obtain for the hot and humid climate of Thailand that performance of a solar chimney results to be more interesting during February to March than from June to October, due to higher temperature differences between the ambient air and indoors.

Wind velocity: Considering existing research on solar chimneys reviewed by Zhai et al [48], these systems are appealing in locations where high solar irradiation is available, but also low wind speeds are desirable to avoid negative airflows that could be generated during long periods of negative DBT-indoor temperature differences. To limit the effect that prevailing wind on solar chimney operation, a wind shield could be utilized [47].

For poor solar irradiance and high outdoor DBT, when solar-induced ventilation is susceptible to be detrimental to indoor thermal comfort, thanks to their design, solar chimneys can be closed to act as mere thermal insulation [43]. Nonetheless, the possibility of integrating them with auxiliary natural cooling systems such as evaporative cooling can also be considered. Maerefat and Haghighi [49] demonstrated that a solar chimney could be beneficial to indoor conditions even for outdoor DBT up to $40^{\circ} \mathrm{C}$ and solar intensity being limited to $200 \mathrm{~W} / \mathrm{m}^{2}$ (including zeroradiation conditions during nighttime). This is possible if the system is properly combined with an evaporative cooling cavity when relative humidity stays below $50 \%$. Actually, in these cases relative humidity arises as a further parameter to be considered. Nevertheless, feasibility of evaporative cooling is studied in more detail in Subsection 3.3.

Chungloo and Limmeechokchai [47] propose spraying water on the roof to increase the temperature differences that enhance the buoyancy effect in the solar chimney. Raman et al [50] demonstrate that a solar chimney equipped with an adequately designed evaporative cooling solution could achieve summer cooling expected in order to be applicable in composite climates like the case of India. Other research work approach this combination of Solar chimney- Evaporative Cooler [48, 49, 51, 52], highlighting that for harsher conditions in which also relative humidity avoids feasibility of evaporative cooling, even dehumidification, active solar and conventional air-conditioning systems might be necessary. 
Table 1: Review of climate considerations for interesting applications of solar passive strategies.

\begin{tabular}{|c|c|c|c|}
\hline $\begin{array}{l}\text { PASSIVE and LOW } \\
\text { ENERGY } \\
\text { STRATEGIES for } \\
\text { thermal comfort }\end{array}$ & $\begin{array}{l}\text { Climate Key } \\
\text { Parameters }\end{array}$ & $\begin{array}{l}\text { Optimal climate } \\
\text { conditions }\end{array}$ & Reference \\
\hline $\begin{array}{l}\text { Solar passive: } \\
\text { Trombe wall }\end{array}$ & \multirow[t]{2}{*}{$\begin{array}{l}\text { - Solar irradiation } \\
\text { - Outdoor DBT* }\end{array}$} & Cold climates & \multirow[b]{2}{*}[42,41,44]{} \\
\hline $\begin{array}{l}\text { Trombe wall } \\
\text { +shading } \\
\text { +ventilation and } \\
\text { insulation options }\end{array}$ & & $\begin{array}{l}\text { Acceptable for mild } \\
\text { and hot climates }\end{array}$ & \\
\hline $\begin{array}{l}\text { Solar passive: } \\
\text { Solar chimney }\end{array}$ & $\begin{array}{l}\text { - Solar irradiation }{ }^{* \star} \\
\text { - } \text { Outdoor DBT }^{*} \\
\text { - Wind direction }{ }^{* *} \text {. }\end{array}$ & $\begin{array}{l}\text { High solar irradiation } \\
\text { and low wind speed }\end{array}$ & {$[48,51]$} \\
\hline $\begin{array}{l}\text { Solar chimney } \\
\text { +insulation options }\end{array}$ & $\begin{array}{ll}\text { - } & \text { Solar irradiation } \\
\text { - } & \text { Outdoor } \mathrm{DBT}^{*} \\
\text { - } & \text { Wind direction. }\end{array}$ & $\begin{array}{l}\text { Acceptable for hot } \\
\text { climates }\end{array}$ & [43] \\
\hline $\begin{array}{l}\text { Solar chimney } \\
\text { +evaporative cooling }\end{array}$ & $\begin{array}{ll}\text { - } & \text { Solar irradiation } \\
\text { - } & \text { Outdoor DBT* } \\
\text { - } & \text { Wind direction. } \\
\text { - } & \text { Relative Humidity }\end{array}$ & $\begin{array}{l}\text { Acceptable for lower } \\
\text { solar irradiation and } \\
\text { high DBT; } \mathrm{RH}<50 \%\end{array}$ & {$[49,52,47]$} \\
\hline
\end{tabular}

${ }^{*}$ Requires further information about *indoor conditions or ${ }^{* *}$ the particular location.

Figure 1 shows the average solar irradiation that could be expected during a typical day for each month, for the climates selected in Subsection 1.2. Although these data are required to foresee passive solar strategies potential, it is given together with daytime typical DBT oscillation in order to analyze possibilities of adaptation during summer period.

Regarding the ideas previously reviewed, high extreme daytime DBT would make solar strategies not recommendable as ventilation devices during cooling season, despite high irradiance levels. This is the case for Las Vegas (Figure 1c) for the whole summer and the interseasonal periods; and for Valladolid (Figure 1a), for the months from June to September. Consequently, at these locations passive solar systems would probably need to act as thermal insulation during long periods, and an adequate design of shadow devices regarding the corresponding solar chart would be essential. Further possibilities by combination with evaporative cooling devices could be considered, having into account the considerations developed in subsequent Section 3.3. 
Concerning the case of Sidney, for the months from October to February (summer period in the southern hemisphere) the highest expected temperatures rarely exceed $30^{\circ} \mathrm{C}$. This could be compatible with indoor comfort if the available irradiation succeeds to achieve important air velocities indoors, as reviewed by Givoni [53], as air velocities and turbulence improve comfort sensation indoors in warm humid climates [54]. However, lower levels of the available irradiation could make it difficult to improve the buoyancy effect to achieve these air speeds. In this sense, London shows the most restricting conditions, because despite milder DBT during cooling season, it is unlikely that the passive solar systems could have enough potential to enhance ventilation, due to the low irradiance levels.

Because solar heating of air is only one of the many factors that favor ventilation for comfort, the next section goes into detail about natural ventilation.

\subsection{Natural ventilation and free-cooling}

\subsubsection{Natural ventilation:}

In order to cover the needs for a proper Indoor Air Quality, ventilation is always required to replace foul air by fresh clean air. Interest on natural ventilation in terms of energy efficiency relies on the fact that it avoids mechanical devices to renew the air, with the consequent economic and environmental implications [55]. Moreover, if outdoor conditions are adequate or considerable air speed is originated indoors, air renewing may directly achieve comfort conditions. Results reviewed by Givoni [53] demonstrate that such comfortable indoor environments can be provided for outdoor air temperatures of up to $29^{\circ} \mathrm{C}$ (and even $34^{\circ} \mathrm{C}$ ) if air velocity reaches 2-3 m/s. Parys et al [56] also proved that office buildings in temperate climates can be successfully cooled simply by window opening control.

Because forces that enable it are buoyancy effect and wind, these have to be defined precisely to predict natural ventilation rates, despite difficulties inherent to this task. The different parameters studied in the reviewed works are described next.

DBT-Indoor temperature difference: outdoor DBT affects ventilation rates, as difference to indoor air temperature, and thus density difference, is responsible of buoyancy effect [57]. However, further factors directly related to the building and indoor environment such as internal heat sources or envelope are crucial to this effect and DBT is insufficient to characterize it. Li\&Desante [58] study this effect on a single-zone naturally ventilated building and outlines the influence of the heat loss of the building.

Solar radiation: As stated before, stratification enhances air movement indoors due to buoyancy effect, and this can be increased by solar radiation [57]. Different passive constructive designs have been developed to benefit from solar heating for ventilation as reviewed by Abreu et al. [59]. Due to this interest, a first-stage design would focus on available radiation, studied through the parameters previously cited in section 3.1. 
Wind velocity and direction: Many studies deal with the issue of how wind interacts with buoyancy effect. Li\&Desante [58] observe that the influence of the building heat loss on natural ventilation is importantly affected by wind force. Lishman\&Woods [60] focus their study on the causes that transform natural ventilation between wind-dominated and buoyancy-dominated, which could lead to indoor discomfort. As an interesting result from the point of view of the climate is that for typical buildings they identify a minimum level of wind of 2-3 m/s for which natural ventilation is dominated by this effect. It is also essential to determine which effect is dominant, because for cooling needs wind-driven flows might be preferable than buoyancydriven patterns, as studied by Yuan\&Glicksman [61]. They determined that if the first situation was originated when initial room temperature was lower, whereas the second one occurred when this initial temperature was relatively high. Nonetheless, even the simplest ways to ventilate such as single-sided ventilation are determined by wind speed and also the incident angle [62]. In fact, the angle of incidence is crucial to ascertain the dominating force among wind pressure or temperature difference in these cases [63] and will depend on building characteristics but also on wind's direction fluctuation. Ji et al [64] concluded that on the overall the most expected wind directions concentrate within $\pm 45^{\circ}$ the prevailing direction, and that it fluctuates in periods from 5 to 30 minutes, and despite little work exists on this subject, it should be taken into account for importantly influencing the performance of natural ventilation. On the other hand Omer [54] states that Single-sided windows are not considered to be adequate for winter ventilation, being only interested in mild climates, and cleverly designed mixed-flow ventilation could favor the buoyancy effect for more exigent cases.

Table 2: Review of climate considerations for interesting application of ventilation strategies.

\begin{tabular}{|c|c|c|c|}
\hline $\begin{array}{l}\text { PASSIVE and LOW } \\
\text { ENERGY } \\
\text { STRATEGIES for } \\
\text { thermal comfort }\end{array}$ & $\begin{array}{l}\text { Climate Key } \\
\text { Parameters }\end{array}$ & $\begin{array}{l}\text { Optimal climate } \\
\text { conditions }\end{array}$ & Reference \\
\hline $\begin{array}{l}\text { Ventilation } \\
\text { Natural (daytime) } \\
\text { ventilation }\end{array}$ & $\begin{array}{ll}\text { - } & \text { Wind velocity** } \\
\text { - } & \text { Wind direction }{ }^{* *} \\
\text { - } & \text { Outdoor DBT }{ }^{*} \\
\text { - } & \text { Relative Humidity }\end{array}$ & $\begin{array}{l}\text { - Prevailing favorable } \\
\text { wind directions } \\
\text { - High wind speed } \\
\text { - Outdoor DBT slightly } \\
\text { over comfort }\end{array}$ & $\begin{array}{c}{[53,65,57,60,} \\
66]\end{array}$ \\
\hline -Single-sided & $\begin{array}{ll}\text { - } & \text { Wind velocity } \\
\text { - } & \text { Wind direction } \\
\text { - } & \text { Outdoor DBT }\end{array}$ & & {$[62,63]$} \\
\hline -Cross ventilation & - Wind direction & & [64] \\
\hline -Stack ventilation. & $\begin{array}{ll}\text { - } & \text { Outdoor DBT* } \\
\text { - } & \text { Wind velocity } \\
\text { - } & \text { Wind direction }\end{array}$ & & {$[67,68]$} \\
\hline
\end{tabular}


-Wind towers.

- Wind direction**

[69]

${ }^{\star}$ Requires further information about *indoor conditions or **the particular location.

However, these parameters also depend on further location-related factors that are not directly involved with the climate, namely altitude, land topography or urban areas. Threrefore, they have to be considered for studying any passive ventilation solution $[68,70]$.

\subsubsection{Free-cooling}

Free-cooling techniques can aim to minimize cooling load of the building through its thermal inertia or diminishing the chilling requirements of the auxiliary cooling system [71]. Taking profit of thermal inertias can be exploited through Phase Change Materials and has been recently and exhaustively reviewed by Alizadeh\&Sadrameli [72]. This approach falls beyond the scope of this work for being intrinsically dependent of the PCMs.

Being driven from outdoors, ventilation usually penalizes the heating and cooling energy demand. Nevertheless, when outdoor conditions drop below the comfort levels during cooling periods, increasing ventilation rates turns to be beneficial [73]. This way of cooling is actually called "free-cooling". Although favorable conditions for such mode of operation is usually associated to night ventilation during the cooling season, effectiveness also depends on outdoor diurnal temperatures.

Givoni [53] stated that only if daily temperature drifts are greater than ${ }^{\circ} \mathrm{C}$, (which normally corresponds to hot and dry regions), it seems to be possible to cool the building thermal mass enough to act as a heat sink during day time. This is for example the case of the city of Madrid, where different passive strategies have been successfully implemented due to the high temperature differences along the day [74]. Consequently, passive cooling potential through night ventilation focus on continental regions, where high daytime and low nighttime temperatures occur [75].

Next, these and other relevant parameters for the estimation of free-cooling potential are commented:

Minimum night-DBT: The minimum temperature reached at night is thus the key climatic parameter to determine night ventilation cooling capacity. This potential can be approached through the calculus of degree-hours without specifying any building parameter, by considering as a reference the harmonically variable building temperature defined by Artmann et al. [70]. Their results highlight the nighttime ventilation cooling potential in Northern Europe, and the existent possibilities in the remaining regions, with the exception of the warmest part of Southern Europe. 
Wind velocity and direction: either nighttime or daytime ventilation is affected by wind (leaving behind building design to enhance favorable air flows indoors); consequently wind parameters previously described in subsection 3.2.1 have to be examined.

Relative Humidity: Results for warm climates show that free-cooling performance also heavily depends on the ambient humidity. Natural ventilation enlarges energy savings only in case of dry conditions, whereas for humid climates night ventilation is preferable. However, in addition to humidity information, savings depend on the building heat capacity, as stated by OropezaPerez\&Ostergaard [76].

In Figure 2, minimum night-DBT during cooling months are represented for the four analyzed climates. It is shown in contrast to the maximum daytime-DBT occurring on the 24-hour period after or before the minimum night-DBT condition. Coincident Relative Humidity is also given to understand the expected humidity levels.

Night ventilation during summer attains its maximum potential when high temperature drifts are obtained from nighttime to daytime. Consequently, this will be a key option for climates such as those of Valladolid or Las Vegas, where temperature drifts of up to $22{ }^{\circ} \mathrm{C}$ and $16{ }^{\circ} \mathrm{C}$ respectively can be expected. This solution is particularly interesting for Valladolid since nighttime DBT can drop below $12 \stackrel{\circ}{\mathrm{C}}$.

As far as it concerns to London and Sidney, the observed lower temperature drifts make night ventilation less appealing in contrast to natural ventilation during daytime, when milder outdoor DBT would favor comfort. Actually, given that relative humidity does not exceed $60 \%$ in any case, natural ventilation in these climates could still be interesting without harming energy savings due to dehumidification needs. To optimize either nighttime or daytime ventilation, paying attention to wind data is also crucial.

Free-cooling simply uses ventilation to remove heat from indoors when outdoor conditions are favorable; consequently it is of great effectiveness [9]. Because cooling potential through ventilation relies on how much favorable outdoor conditions are, appropriate control is essential and so it is the study of the climate. Numerous research works have focused on the interest of performing free-cooling control through different parameters and set points.

DBT: A rough but clear indicator for the free-cooling potential is the outdoor air dry bulb temperature, as it determines the operation of a building free-cooling system [77]. A possible way to analyze the applicability of free-cooling is to provide a probabilistic distribution of the outdoor temperature, as performed by Inard et al. [78]. When DBT falls down the value upon which cooling needs are expected, these might be covered through free-cooling. According to this, applicability of free-cooling can be illustrated by the number of hours of application through the bin weather data, considering the supply air temperature as the reference value. However, it is of vital importance to fairly estimate this base temperature, because it clearly affects the calculations on the free-cooling potential. Results obtained by Bulut and Acktacir in Istambul [79] for various base temperatures demonstrate that inter-seasonal months constitute the ideal 
period to use this cooling technique. If cooling demand extends to the whole year, free-cooling applicability does not restrict to inter-seasonal periods and attains interest that is even more notable. This happens in particular cases such as data centers, for which a fixed supply air temperature of $15^{\circ} \mathrm{C}$ can be considered to ensure the required indoor thermal conditions [ 80 , 81]. Free-cooling acquires here such interest, that numberless research works have been developed.

DBT-Indoor temperature difference: One possibility is to consider indoor dry bulb temperature as the reference value (base Temperature) to estimate free-cooling potential [79]. As indoor temperature also depends on the building information, for a general study it can be defined within the comfort ranges $[82,83,84]$. When this difference is favorable, it indicates that at least no ventilation gains are to be covered by an existing air-conditioning system. In order to perform a careful study of the potential for covering additional gains through free-cooling strategies, more information on the particular application would be needed.

Free-running temperature: When only natural ventilation exists and adaptive thermal comfort models are applicable [85], a more adequate tool to predict free-cooling potential might be the free-running temperature. The building free-running temperature characterizes the thermal building behavior and the frequency distribution of the outdoor temperature to describe the climate, similar to the bin method. However, as indicated by Inard et al. [78] additional information on building characteristics is needed, namely supplied airflow and heat gains.

Yet, dry bulb temperatures are not always sufficient to determine whether the direct supply of outdoor air is efficient or not. Actually, enthalpy control is recommendable when the outdoor air relative humidity may reach extreme conditions, because the energy consumption increases due to the humidification or dehumidification requirements. In this sense, interesting outdoor conditions can be limited regarding Relative Humidity and the Dew Point Temperature (DPT):

DPT and $\mathrm{RH}$ : Especially for data center applications, the supplied relative humidity should be restricted because of the potential risks for the equipment. Nonetheless, humidification and dehumidification processes are usually disregarded because of the involved energy consumption. Some authors $[86,87]$ demonstrated that energy required for dehumidification hinders potential energy savings by free-cooling when outdoor DPT falls significantly below the DPT indoor level. They proposed conditions to be between DPT from $5.5^{\circ} \mathrm{C}$ to $15^{\circ} \mathrm{C}$ for data centers with DBT of 18 to $27^{\circ} \mathrm{C}$, which correspond to $\mathrm{RH}$ of $60 \%$. This restriction is also implemented in table 4. Consequently, climates with mixed-humid, warm-marine, and mixedmarine conditions achieved high energy savings through free-cooling implementation, whereas it was not recommendable for very cold, subarctic, cool-dry, and cold-dry climate zones [14, 15].

On the other hand, weather effect on the building's thermal response is more complex, being the wind speed and direction, solar radiation, etc. also influencing variables. Consequently, according to Dovrtel\&Medved [77] an optimal free-cooling control would require all this information. 
Table 3: Review of climate considerations for interesting application of free cooling.

\begin{tabular}{|c|c|c|c|}
\hline $\begin{array}{l}\text { PASSIVE and LOW } \\
\text { ENERGY } \\
\text { STRATEGIES for } \\
\text { thermal comfort }\end{array}$ & $\begin{array}{c}\text { Climate Interesting } \\
\text { Parameters }\end{array}$ & $\begin{array}{l}\text { Optimal climate } \\
\text { conditions }\end{array}$ & Reference \\
\hline $\begin{array}{l}\text { Free-cooling } \\
\text { Night ventilation }\end{array}$ & - Min. Night DBT* & $\begin{array}{l}\text { High daytime DBT and } \\
\text { low nighttime DBT }\end{array}$ & {$[53,75]$} \\
\hline $\begin{array}{l}\text { Free-cooling } \\
\text { Daytime free-cooling }\end{array}$ & $\begin{array}{l}\text { - } \\
\text { - Outdoor DBT } \\
\text { - Outdoor DPT } \\
\text { Outdoor RH }\end{array}$ & $\begin{array}{l}\text { Outdoor DBT below } \\
\text { comfort. } \\
\text { Outdoor } \mathrm{DBT}<15^{\circ} \mathrm{C} \\
\text { Inter-seasonal periods } \\
\text { mixed-humid, warm- } \\
\text { marine, and mixed- } \\
\text { marine climates }\end{array}$ & $\begin{array}{c}{[9,77,78,79,} \\
\quad 80,81]\end{array}$ \\
\hline
\end{tabular}

${ }^{*}$ Requires further information about *indoor conditions or ${ }^{* *}$ the particular location.

The number of hours of free-cooling availability according to the base temperatures proposed by Bulut\&Aktacir [79] $\left(24^{\circ} \mathrm{C}, 21^{\circ} \mathrm{C}, 18^{\circ} \mathrm{C}\right.$ and $\left.15^{\circ} \mathrm{C}\right)$ are gathered in Table 4 for each one of the analyzed climates. Results are presented both on a yearly basis and limited to a standard cooling period (May to September for locations in the Northern hemisphere and October to February for Sidney). Moreover, data are provided according to three different conditions for the target period of evaluation. The first one considers every hour along the day $(24 \mathrm{~h} / \mathrm{day}$ condition), the second one limits the evaluation to a common office working schedule (from 8.00 a.m. to 8.00 p.m.), and finally, the third one is based on the $24 \mathrm{~h} /$ day condition with an additional restriction on the relative humidity level (only hours with $\mathrm{RH}<60 \%$ are evaluated). This last restriction is proposed to show the free-cooling potential for data center applications according to the work of Dai et al. [86] and Lee and Chen [87].

Table 4.: Free cooling potential (number of hours of applicability) for different base temperatures, working period and relative humidity restrictions for the four climates studied.

VALLADOLID

\begin{tabular}{|ccccccc|}
\hline & \multicolumn{2}{c}{$(24 \mathrm{~h} /$ day $)$} & \multicolumn{2}{c}{ (8 a.m. -8 p.m. $)$} & \multicolumn{2}{c|}{$(24 \mathrm{~h} /$ day $)$} \\
& $(\mathrm{RH}<60 \%)$ \\
\hline T_base & Whole & Cooling & Whole & Cooling & Whole & Cooling \\
(C) & year & season & year & season & year & season \\
\hline 24 & 8032 & 2954 & 4022 & 1276 & 2985 & 1811 \\
\hline
\end{tabular}




\begin{tabular}{|llllccc|}
\hline 21 & 7482 & 2451 & 3544 & 845 & 2435 & 1308 \\
18 & 6713 & 1780 & 3064 & 461 & 1706 & 677 \\
15 & 5647 & 1000 & 2532 & 193 & 922 & 149 \\
\hline
\end{tabular}

LONDON

\begin{tabular}{|ccccccc|}
\hline & \multicolumn{2}{c}{$(24 \mathrm{~h} /$ day $)$} & \multicolumn{2}{c}{$(8$ a.m. -8 p.m. $)$} & \multicolumn{2}{c|}{$(24 \mathrm{~h} /$ day $)$} \\
$(\mathrm{RH}<60 \%)$
\end{tabular}

LAS VEGAS

\begin{tabular}{|ccccccc|}
\hline & \multicolumn{2}{c}{$(24 \mathrm{~h} /$ day $)$} & \multicolumn{2}{c}{$(8$ a.m. -8 p.m. $)$} & \multicolumn{2}{c|}{ (24 h/day) \& $(\mathrm{RH}<$} \\
\hline T_base & Whole & Cooling & Whole & Cooling & Whole & Cooling \\
(C) & year & season & year & season & year & season \\
\hline 24 & 5640 & 886 & 2618 & 184 & 4960 & 826 \\
21 & 4919 & 470 & 2282 & 94 & 4254 & 425 \\
18 & 4111 & 205 & 1825 & 57 & 3471 & 185 \\
15 & 3346 & 93 & 1333 & 25 & 2720 & 79 \\
\hline
\end{tabular}

SIDNEY

\begin{tabular}{|ccccccc|}
\hline & \multicolumn{2}{c}{$(24 \mathrm{~h} /$ day $)$} & \multicolumn{2}{c}{$(8$ a.m. -8 p.m. $)$} & \multicolumn{2}{c|}{ (24 h/day) \& $(\mathrm{RH}<$} \\
\hline T_base & Whole & Cooling & Whole & Cooling & Whole & Cooling \\
(C) & year & season & year & season & year & season \\
\hline 24 & 7775 & 2851 & 3880 & 1301 & 1335 & 378 \\
21 & 6181 & 1805 & 2851 & 667 & 960 & 176 \\
18 & 4391 & 841 & 1840 & 206 & 574 & 42 \\
15 & 2632 & 246 & 924 & 29 & 211 & 0 \\
\hline
\end{tabular}

For the case of Valladolid, despite large periods of free-cooling applicability during summer (near half of the total number of hours for the most restricted base temperature, of $15^{\circ} \mathrm{C}$ ), this period of application is limited to less than a fifth if restricted to working hours. This can be explained considering the high temperature drifts along a day during the cooling season, what was already observed in Figure 2. Considering the additional limitation on the relative humidity required for data centers in a whole year, free-cooling would provide the required supply conditions during about $10 \%$ of the time for the most exigent base temperature and $35 \%$ of the time for a Tbase of $24^{\circ} \mathrm{C}$. 
In the case of Las Vegas, the number of hours when free-cooling would be interesting, diminishes from the values for Valladolid for every reference temperature. This is because of the harsher conditions, especially during the cooling season. However, due to the low relative humidity expected, appropriate conditions for data centers would be also provided during the same period.

London and Sidney present ideal conditions for free-cooling application for the whole year if not very exigent base temperatures are set. In addition, the restriction to a typical working timetable in summer does not introduce so big differences as for Las Vegas or Valladolid, what can be explained according to the lower daily temperature drifts. However, higher outdoor DBT temperatures expected in Sidney during daytime in summer notably reduce its potential within this period. Besides, higher humidity makes these climates less interesting for data center applications.

\subsection{Evaporative cooling}

Evaporative cooling phenomenon enables heat dissipation using water as a sink, thanks to the energy required in the heat and mass transfer due to water evaporation into the ambient air. It might be the oldest air-conditioning option, and there are indeed a number of examples of traditional applications, sometimes implemented in combination with natural ventilation strategies [48] and solar passive cooling systems [50]. Nevertheless, its interest persists mainly due to its cheapness, simplicity and low energy consumption.

Evaporative cooling systems can be classified into three types: direct, indirect and multi-stage systems (which benefits from different combinations of the other two) [88]. Evaporative cooling strategies can also be implemented in the own windows or roof of the target space [89]. They are expected to be appealing in hot and dry regions, but every previous work in this field agrees on the fact that careful analysis of specific climate conditions is needed to ensure particular feasibility of each option. Those relevant parameters for the estimation of the evaporative cooling potential are discussed next:

Dry Bulb Temperature (DBT): In Direct Evaporative Coolers (DEC), the amount of energy required to evaporate water is obtained from the same airflow being conditioned, which reduces its DBT along the process. On the overall, thermal effectiveness increases with DBT of the inlet air, as observed in tests performed on DEC devices: DBT drops of up to $7.4{ }^{\circ} \mathrm{C}$ were shown on the research conducted by Camargo et al. [90] and similar results were obtained for a $540 \mathrm{~m}^{3} / \mathrm{h}$ airflow in ceramic prototypes by Velasco et al. [91]. For mild temperatures, as the typical ones in temperate climates, evaporative cooling has been demonstrated to still be appealing, by using Indirect Evaporative Coolers (IEC) [92]. However, considering DBT is far from being enough to determine evaporative cooling potential.

Wet Bulb Temperature (WBT) and Wet Bulb Depression (WBD): The key climatic variable to determine whether evaporative cooling is of interest is the WBT, or similarly the Adiabatic 
Saturation Temperature (AST) [92, 93], because it determines the limit for the achievable cooled temperature. Regarding the WBT, evaporative cooling potential can be measured through the WBD as the difference between the DBT and its coincident WBT [94, 95, 96]. Actually, achieved temperature drops increase with the WBD, which justifies the expected interest of evaporative cooling in arid regions, as demonstrated by Krüger et al [97]. Besides, according to Smith et al. [98] the prediction of WBD increase in future scenarios due to climate change broadens the applicability of evaporative cooling in temperate climates, where nonetheless IEC are always interesting.

Enthalpy difference outdoors-indoors: Lazzarin\&Noro [71] study the cooling potential of DEC and IEC techniques applied to four cities representative of three climates among the most common in Europe. The parameters they analyze are the air enthalpies and humidity ratios: DEC would then be useful if outside air enthalpy is lower than inside's, together with an also lower humidity ratio. On the contrary, IEC could be applicable even if outside air enthalpy is over that of indoors, provided that it succeeds to decrease below that value after the IEC. This idea enables them to divide the psychrometric chart into 7 operating regions for DEC and IEC. They present the percentage of time during which DEC and IEC would operate within each of the respective 7 zones of psychrometric conditions. Corresponding cooling potential and energy savings demonstrate that IEC results more interesting for every city studied, but particularly for those corresponding to Csa climates.

Figure 3 shows bin data of wet bulb depression temperatures during cooling season for the four analyzed climates. Climates with dry summers such as Valladolid and Las Vegas present WBD values of up to $20^{\circ} \mathrm{C}$ and $26^{\circ} \mathrm{C}$ respectively, which makes DEC of great interest (provided that water resources are always available). However, for humid summers like the case of London or Sidney, where WBD are not relevant during long periods, the application of IEC or combined systems would be preferable according to the results reviewed. In these cases, efficiency could be improved by using exhaust air as the secondary air stream when possible.

Taking into consideration those limitations highlighted by WBD, IEC broadens the applicability of evaporative cooling despite being less efficient than DEC [99]. Nonetheless, Wong and Chong [100] have implemented DEC systems even with high humidity rates observing acceptable results on the occupants' thermal sensation. However, the disadvantages derived from working with high Relative Humdity $(\mathrm{RH})$ values are not only referred to the loss of effectiveness and thermal comfort, but also to the risk of organic growth. Consequently, for slightly high WBT (over $21^{\circ} \mathrm{C}$ ), combining stages of DEC and IEC may be an effective choice [101]. Morgado-Baca et al. [102] propose a methodology to evaluate combinations of DEC and IEC for different Spanish climates and calculate percentages of comfort achieved. Rodríguez-Ubinas et al. [74] demonstrate that direct water evaporation into the air expands the hours of indoor thermal comfort up to $98 \%$ of the cooling period in Madrid, and also analyze two-stage possibilities. Nonetheless, for even higher outdoor humidity conditions these options should be disregarded. In such situations, a recommendable alternative is based on energy recovery, which uses return air from the conditioned space as secondary airflow for IEC [103], [104]. 
It must be noted that there are other factors, apart from the parameters DBT and WBT, which affect feasibility of the different evaporative cooling systems. Although indoor conditions do not influence IEC effectiveness if operating with outdoor air, they do limit evaporative cooling applicability if restricted humidity values are required indoors. Consequently, further parameters than those strictly related to the climate are needed for a complete study. Among these possible parameters the following deserve mentioning: the cooling potential index, which is the difference between outdoor and indoor temperature [105]; the space sensible heat factor, which represents the quality of space load; and the performance index of the system [106]. Considering all these factors, restricting the study to the climate conditions can result in a fair first evaluation regardless of the influence of building and comfort conditions.

Table 5: Review of climate considerations for interesting application of evaporative cooling.

\begin{tabular}{|c|c|c|c|}
\hline $\begin{array}{c}\text { PASSIVE and LOW } \\
\text { ENERGY } \\
\text { STRATEGIES for } \\
\text { thermal comfort }\end{array}$ & $\begin{array}{c}\text { Climate Interesting } \\
\text { Parameters }\end{array}$ & $\begin{array}{l}\text { Optimal climate } \\
\text { conditions }\end{array}$ & Reference \\
\hline $\begin{array}{l}\text { Evaporative cooling } \\
\text { DEC }\end{array}$ & $\begin{array}{ll}\text { - } & \text { Outdoor DBT } \\
\text { - } & \text { Outdoor RH (WBT) } \\
\text { - } & \text { Outdoor-indoor } \\
& \text { Enthalpy difference }\end{array}$ & $\begin{array}{l}\text { Hot and dry climates } \\
\text { Humid climates } \\
\text { (limited) } \\
\text { Cfb, Csb, Csa climates }\end{array}$ & $\begin{array}{c}{[90,91]} \\
{[100]} \\
{[71]}\end{array}$ \\
\hline $\begin{array}{l}\text { Evaporative cooling } \\
\text { IEC }\end{array}$ & $\begin{array}{l}\text { - Outdoor DBT } \\
\text { - Indoor enthalpy }\end{array}$ & $\begin{array}{l}\text { Hot and dry climates } \\
\text { Temperate climates } \\
\text { Cfb, Csb, Csa climates }\end{array}$ & $\begin{array}{c}{[97,99]} \\
{[92,93,98]} \\
{[71]}\end{array}$ \\
\hline $\begin{array}{l}\text { Evaporative cooling } \\
D E C+I E C\end{array}$ & - $\quad$ Outdoor DBT & $\begin{array}{l}\text { Hot and dry, or } \\
\text { temperate and more } \\
\text { humid climates }\end{array}$ & {$[101,102]$} \\
\hline $\begin{array}{l}\text { Evaporative cooling } \\
I E C+\text { heat recovery }\end{array}$ & $\left(\right.$ None directly) ${ }^{*}$ & Humid climates & {$[103,104]$} \\
\hline
\end{tabular}

${ }^{*}$ Requires further information about *indoor conditions or **the particular location. 


\section{Collection and representation of climatic data}

The previous review work of targeting the key climate parameters underlines the importance of weather when selecting the most appropriate passive alternatives. To quicken this decision, selected climate data can be gathered into different tools that ease the representation of such amount of information.

There exist a proposal of compilation of parameters on a table by ASHRAE [107], for a simple gathering of design conditions and most relevant climatic information. Concise weather design data provides a useful tool to estimate heating and cooling requirements and analyze equipment dimensioning, provided that available data is updated [108], [109]. Besides, tabulation of probable and extreme climate conditions can be useful to classify climate regions and select passive strategies accordingly, which in most cases coincides with vernacular architectural designs, as it happens, for instance, in North-east India [110].

Apart from this simple collection of data, the objective of using climate information to seek sustainable methods intended for thermal comfort provision, leads to a number of more or less complex data representations. Tables given by Mahoney do not only provide interesting climatic variables, but also identifies different climates according to humidity, propose climatic indicators and introduce recommendations. This method is used to approach the analysis of the climate of Nicosia (Cyprus) for an efficient passive design [111]. Besides, alternative indices have been defined and compared, turning to be interesting for all climates with the exception of hot and humid ones [112].

Psychrometric diagrams offer a more illustrative option to represent the TMY conditions of a particular site, in contrast to gathering climate data on a table. A bioclimatic chart is a sort of graph, based on a psychrometric diagram, which results to be a clearer way to give an idea of the local outdoor conditions to be faced, as well as target comfort conditions. Thus, the actual possibilities of passive resources to simultaneously achieve comfort indoors and reduce energy consumption are revealed [113]. Climatic charts are the graphical result of an old study on the relationship between man and climate, and the variables involved in this relationship. Szokolay defines the Control Potential Zone (CPZ) to identify psychrometric conditions with optimal conditioning strategies. It is constructed from existing bioclimatic work, considering the approach given by the Mahoney tables, showing the monthly maximum and minimum DBT and corresponding $\mathrm{RH}$ [114], [111].

Among the numerous climate charts developed, the first proposal by Olgyay [115] and the most spread chart of Givoni [116] stand out. For the first time, Olgyay implements a region of thermal comfort within the psychrometric diagram, accounting for the DBT ( $\left.{ }^{\circ} \mathrm{F}\right)$ and $\mathrm{RH}(\%)$ as the basic variables that affect to human thermal sensation. This region is also identified as the one that requires minimum energy consumption for comfort to be achieved. However, it does not consider important factors about the modification of outdoor climate conditions or about comfort aspects, such as the metabolic rate or the radiant mean temperature. 
For his part, Givoni proposes a widespread alternative to overcome some of the problems highlighted in the Olgyay's proposal and extends the ASHRAE comfort standards. This bioclimatic chart is based on a psychrometric diagram where outdoor climate conditions are represented, usually in the form of segments showing monthly oscillation from minimum DBT and maximum $\mathrm{RH}$ to maximum DBT and minimum $\mathrm{RH}$. These segments are represented for Valladolid in Figure 4.

This sort of view of outdoor conditions results clearer than cluster of dots representation, as the diagram given in Figure 5.

Additionally, boundaries are defined for applicability of different passive design strategies or a combination of them, based on the expected indoor conditions achievable through them (Figure 6 [116], [117], [118]).

Passive strategies, including those previously reviewed, have been studied for particular climates from the viewpoint of the Givoni bioclimatic chart. This analysis demonstrates the utility of this asset for evaluating the most favorable sustainable strategy. Existing research on this issue can be of great interest as a guide for future sustainable designs. By means of this it can be determined the percentage of hours during which thermal comfort is achieved through different passive options.

Multiple authors have worked on determining the periods when thermal comfort is achievable through different techniques. Indeed, this study has been developed for multiple climates in Egypt, focusing on outdoor resources [119]. In this way, nine different zones have been distinguished for China, where optimal passive techniques have been proved to be effective in summer and winter, restricting the percentage of operation of conventional air-conditioning systems in summer to $25-50 \%$ corresponding to the most unfavorable region [120]. Also for Madagascar different climate zones have been defined according to the solar potential, proposing the optimal passive strategies all throughout the year [121]. Assessment of the different passive techniques has also been possible through bioclimatic charts for the different climate regions in Oman, as climate variables have most weight than the remaining factors such as cultural or situational ones [113]. Besides, passive solutions recommended through the study of bioclimatic charts can be identified in traditional buildings cleverly constructed for the different climates, as the case of Nepal [122]. Anyway, such thorough studies can lead to a revision of the applicability of the boundaries defined by Givoni, as happens in the case of DEC and night ventilation in Seville [117]; or for composed climates as that of the city of Belo Horizonte in Brazil, where recommendations might be contradictory [123].

Knowledge on the exact periods of applicability can overcome possible problems of lessening energy efficiency due to an inadequate selection of passive techniques, which in some cases are counterproductive during certain seasons. With this aim, a regression model has been proposed relating environmental conditions and passive technologies (as well as building characteristics) to energy efficiency, for a better assessment of the design or even to be considered in new regulations on energy savings and control of $\mathrm{CO}_{2}$ emissions [17]. 
To implement a bioclimatic approach, different software tools have been developed. Guan et al. [118] propose a tool to identify regions of outdoor air conditions on a psychrometric chart, which are suitable for operation of different combined solutions. In their proposal, parameters affecting the desired thermal comfort conditions are also identified. This assessment tool provides as well the number of hours of occurrence of the different regions distinguished. Further software is CLIMATE_CONSULTANT from the University of Los Angeles [124]. However, application of these assets for hot and humid climates could be limited, and in these cases the comfort zone must be redefined according both to the climate and the passive strategy considered. This is the case of Vietnam, for which a specific climate analysis tool has been recently proposed [13]. On the other hand, also for hot and humid climates Givoni bioclimatic chart proved to be preferable among ASHRAE standards [125].

These software also provide other weather information than psychrometric variables, such as wind and solar data, which have been previously highlighted as of interest for passive solutions viability and effectiveness. As an alternative to tabulated wind data, wind roses offer a visual tool to collate monthly prevailing wind directions, frequencies or even velocities. Radiation and solar position can also be gathered monthly, into tables or charts.

Finally, sometimes for a proper feasibility assessment it might be also necessary to study the uncertainty of climate characteristics. This is actually the case when only passive cooling is implemented and adaptive models are considered. Its relevance lies in the fact that passive cooling cannot cover heating and cooling demand to the same range as active cooling does. Monte Carlo uncertainty method has been successfully proposed to evaluate two ventilation passive strategies (window opening and night cooling) considering both building and climate uncertainties, which serves as an example for other strategies [56].

Taking all this into account, a bioclimatic approach is a powerful tool to determine the optimal passive and low energy solutions if appropriate data is available. But, as the end is to achieve comfort indoors, comfort requirements have to be defined in addition to weather information [114]. 


\section{Conclusions and future work}

Many research works have been developed to provide a tool for engineers, architects and government bodies, to design or chose effective passive heating and cooling techniques for a certain climate, as well as to draft legislation accordingly. With this aim, identifying climate parameters affecting effectiveness is a key issue. In this paper, an overview of existing results on the climate factors affecting the passive techniques studied is presented. This would be of great help to foresee viability of any passive solution considered for its installation at a particular location. The following conclusions and issues of further analysis are extracted.

- Careful use of available climate data must be always done, as derives from historical data and thus only represents probable occurrence of conditions. Therefore, extreme conditions cannot be expected from this data. Besides, most climate data is given for a particular point not interfered by surrounding elements, creating unexpected shadowing or protecting from the wind. If possible, it is then always preferable to base the design on weather forecast rather than on the TMY.

- Solar radiation availability is not only interesting for heating during winter, but also to assist buoyancy for ventilation during cooling periods. Solar passive solutions can effectively enhance ventilation in summer through improving the buoyancy effect, if high irradiance levels are expected. However, these data must be contrasted with outdoor DBT. For particularly high DBT values (over $30^{\circ} \mathrm{C}$ ) the operation of solar passive solutions as insulation systems with an adequate shadowing design is more recommendable. On the other hand, solar position is also crucial for an adequate planning of the shading strategy. Moreover, cloudiness would need to be considered in these applications within an expanded analysis.

- Climates with particularly harsh outdoor DBT conditions during summer may show an interesting night-ventilation potential, if high temperature drifts from daytime to nighttime occur. On the other hand, when temperature drifts are not so important, natural ventilation during daytime can still be interesting in climates when summer temperatures are milder, provided that relative humidity keeps relatively low in order to avoid dehumidification needs. Considering wind data is crucial either for daytime or nighttime natural ventilation and should be considered into a next step.

-Regarding the number of hours of applicability referred to different base temperatures, free cooling potential is particularly interesting in mild climates, but if relative humidity frequently exceeds $60 \%$ it loses its interest for data center applications. On the other hand, high temperature drifts expected along a typical day notably reduce the period of applicability of this strategy if daily requirements are restricted to office hours.

- Direct evaporative cooling can approach comfort during summer in a wide range of conditions, despite obtaining lower effectiveness at high relative humidity rates. Besides, DEC is also restricted depending on humidity levels accepted for supplied air. The study of WBT and WBD 
define the applicability limits for DEC, IEC and various-stages options, as well as in combination with other alternatives.

- After having reviewed the key climate parameters to be observed when studying applicability of the proposed passive and low energy solutions, these can be gathered together to provide a quick overview on the climatic potential according to actual research studies (Figures 1 to 3 and Table 4). A compilation of these different data representation then appears as a simpler alternative to existing bioclimatic tools.

Nonetheless, climate conditions are not the only factor to be considered when considering every possible passive strategy. Those further variables are to be studied in a more extended analysis that surpasses the mere climate analysis faced in this work. Some passive and low energy techniques are based on night cooling by radiant dissipation to the sky, which would depend on the sky temperature. However, as it depends heavily on the characteristics of the implemented solution, it is not dealt with here. Concerning the possibility of coupling systems (or even the building) to the ground, this review work could be broadened covering these aspects if information about ground temperatures is available within the weather databases.

Furthermore, climatic conditions at a given location are not just determined by weather data, but are also affected by topography and urban areas. Surrounding geometry modifies wind patterns and also sunlight, as solar radiation might not access obstructed areas. Actual solar radiation falls far from expected levels in the densest urban areas, so better methods to provide accurate determination of the actual radiation incidence are needed. Likewise, climate change and urban heat islands affect real operating conditions and consequently cooling energy consumption. Deepening into these aspects is recommended when studying low-energy possibilities at any site. Finally, a more comprehensive analysis would require information on indoor comfort expectations and building characteristics. 


\section{Acknowledgements}

Paola García Ibáñez would like to thank the support provided by the Ministry of Education through the collaboration grant received for the academic year 2013/2014 in order to carry out a research at the Department of Energy Engineering and Fluid Mechanics of the University of Valladolid.

This paper is based upon work supported by the Spanish Government through the national research project 'OPtimisation of design and integrated operation of Thermo-Active Building Systems (TABS) and LOW-energy sources for Mediterranean climate, OPTABSLOW (Ref.: ENE2014-58990-R) 


\section{Figure captions}

Figure 1: Typical daytime DBT variation and total Solar irradiation for a) Valladolid, b) London, c) Las Vegas and d) Sidney.

Figure 2: Minimum Night-DBT, coincident $\mathrm{RH}$ and corresponding extreme daytime-conditions, during cooling season for a) Valladolid, b) London, c) Las Vegas and d) Sidney.

Figure 3: Wet Bulb Depression Bin-temperatures for a) Valladolid, b) London, c) Las Vegas and d) Sidney.

Figure 4.: Outdoor climate conditions for Valladolid.

Figure 5: Outdoor climate conditions for Valladolid. Cluster of dots.

Figure 6: Comfort zone and boundaries for passive strategies application. 


\section{References}

[1] EPBD recast: Directive 2010/31/EU of the European Parliament and of the Council of 19 May 2010 on the Energy Performance of Buildings (recast). http://eurlex.europa.eu/LexUriServ/LexUriServ.do?uri=OJ:L:2010:153:0013:0035:EN:PDF (Last Access 19-06-2015).

[2] Energy Efficiency Trends in Buildings in the EU: Lessons from the ODYSSEE MURE project. Enerdata; 2012.

[3] Kemna R, Moreno J. Average EU building heat load for HVAC equipment: Final report. Van Holsteijn en Kemna BV; 2014.

[4] World Urbanization Prospects: Highlights. 2014 Revision. United Nations; 2014.

[5] Indoor air pollution: new EU research reveals higher risks than previously thought European Commission - IP/03/1278. EU Commission; 2003.

[6] Wan KKW, Li DHW, Liu D, Lam JC. Future trends of building heating and cooling loads and energy consumption in different climates. Build and Environ 2011;46 (1):223-34.

[7] Samuel DGL, Nagendra SMS, Maiya MP. Passive alternatives to mechanical air conditioning of building: A review. Build and Environ 2013;66:54-64.

[8] Santamouris M, Kolokotsa D. Passive cooling dissipation techniques for buildings and other structures: The state of the art. Energy and Build 2013;57:74-94.

[9] Ghiaus C, Allard F. Potential for free-cooling by ventilation. Sol Energy 2006;80 (4):402-13.

[10] Yang L, Yan H, Lam JC. Thermal comfort and building energy consumption implications - A review. Appl Energy 2014;115:164-73.

[11] Hoyt T, Arens E, Zhang H. Extending air temperature setpoints: Simulated energy savings and design considerations for new and retrofit buildings. Build and Environ 2015;88: 89-96.

[12] Li DHW, Wong SL, Lam JC. Climatic effects on cooling load determination in subtropical regions. Energy Convers and Manag 2003;44 (11):1831-43.

[13] Nguyen AT, Reiter S. A climate analysis tool for passive heating and cooling strategies in hot humid climate based on Typical Meteorological Year data sets. Energy and Build 2014;68 (PART C):756-63.

[14] Peel MC, Finlayson BL, McMahon TA. Updated world map of the Köppen-Geiger climate classification. Hydrol and Earth Syst Sci 2007;11 (5):1633-44.

[15] Kottek M, Grieser J, Beck C, Rudolf B, Rubel F. World map of the Köppen-Geiger climate classification updated. Meteorologische Z 2006;15 (3):259-63

[16] Campaniço H, Hollmuller P, Soares PMM. Assessing energy savings in cooling demand of buildings using passive cooling systems based on ventilation. Appl Energy 2014;134:426-38.

[17] Tzikopoulos AF, Karatza MC, Paravantis JA. Modeling energy efficiency of bioclimatic buildings. Energy and Build 2005;37 (5):529-44.

[18] Frank Th. Climate change impacts on building heating and cooling energy demand in Switzerland. Energy and Build 2005;37 (11 SPEC. ISS.):1175-85.

[19] Christenson M, Manz H, Gyalistras D. Climate warming impact on degree-days and building energy demand in Switzerland. Energy Convers and Manag 2006;47 (6):671-86.

[20] Cartalis C, Synodinou A, Proedrou M, Tsangrassoulis A, Santamouris M. Modifications in energy demand in urban areas as a result of climate changes: An assessment for the southeast Mediterranean region. Energy Convers and Manag 2001;42 (14):1647-56. 
[21] Santamouris M. On the energy impact of urban heat island and global warming on buildings. Energy and Build 2014;82:100-13.

[22] Wang N, Zhang J, Xia X. Energy consumption of air conditioners at different temperature set points. Energy and Build 2013;65:412-8.

[23] Yau YH, Pean HL. The climate change impact on air conditioner system and reliability in Malaysia - A review. Renew and Sustainable Energy Rev 2011;15 (9):4939-49.

[24] Yau YH, Pean HL. The performance study of a split type air conditioning system in the tropics, as affected by weather. Energy and Build 2014;72:1-7.

[25] Sobrinho PM, Tuna CE. Experimental research on the influence of the air humidity conditions in an air conditioning system. Experimental Therm and Fluid Sci 2013;49:152-9.

[26] Radhi H. A comparison of the accuracy of building energy analysis in Bahrain using data from different weather periods. Renew Energy 2009;34 (3):869-75.

[27] Janjai S, Deeyai P. Comparison of methods for generating typical meteorological year using meteorological data from a tropical environment. Appl Energy 2009;86 (4):528-37.

[28] Jiang Y. Generation of typical meteorological year for different climates of China. Energy 2010;35 (5):1946-53.

[29] Wong SL, Wan KKW, Li DHW, Lam JC. Generation of typical weather years with identified standard skies for Hong Kong. Build and Environ 2012;56:321-8.

[30] Ohunakin OS, Adaramola MS, Oyewola OM, Fagbenle RO. Generation of a typical meteorological year for north-east, Nigeria. Appl Energy 2013;112:152-9.

[31] Yang L, Lam JC, Liu J, Tsang CL. Building energy simulation using multi-years and typical meteorological years in different climates. Energy Convers and Manag 2008;49 (1):113-24.

[32] Skeiker, K., Ghani, B.A. A software tool for the creation of a typical meteorological year. Renew Energy 2009;34 (3):544-54.

[33] Guan L, Yang J, Bell JM. Cross-correlations between weather variables in Australia. Build and Environ 2007;42 (3):1054-70.

[34] Medved S, Babnik M, Vidrih B, Arkar C. Parametric study on the advantages of weatherpredicted control algorithm of free cooling ventilation system. Energy 2014;73:80-7.

[35] Givoni B. Performance and applicability of passive and low energy cooling systems. Energy and Build 1991;17:177-99.

[36] Spanish Technical Building Code (CTE): DB HE Energy Saving. Reference climates. http://www.codigotecnico.org/web/recursos/documentos/ (Last Access 11/03/2016).

[37] Meteonorm TMY2 database: www.meteonorm.com (Last Access 11/03/2016)

[38] Quesada G, Rousse D, Dutil Y, Badache M, Hallé S. A comprehensive review of solar facades. Opaque solar facades. Renew and Sustainable Energy Rev 2012;16 (5):2820-32.

[39] Quesada G, Rousse D, Dutil Y, Badache M, Hallé S. A comprehensive review of solar facades. Transparent and translucent solar facades. Renew and Sustainable Energy Rev 2012;16 (5):2643-51.

[40] Zhou J, Chen Y. A review on applying ventilated double-skin facade to buildings in hotsummer and cold-winter zone in China. Renew and Sustainable Energy Rev 2010;14:1321-28.

[41] Saadatian O, Sopian K, Lim CH, Asim N, Sulaiman MY. Trombe walls: A review of opportunities and challenges in research and development. Renew and Sustainable Energy Rev 2012;16 (8):6340-51. 
[42] Stazi F, Mastrucci A, di Perna C. Trombe wall management in summer conditions: An experimental study. Sol Energy 2012;86 (9):2839-51.

[43] Chan HY, Riffat SB, Zhu J. Review of passive solar heating and cooling technologies. Renew and Sustainable Energy Rev 2010;14 (2):781-89.

[44] Ralegaonkar RV, Gupta R. Review of intelligent building construction: A passive solar architecture approach. Renew and Sustainable Energy Rev 2010;14 (8):2238-42.

[45] Littlefair P. Daylight, sunlight and solar gain in the urban environment. Sol Energy 2001;70 (3):177-85.

[46] Tzempelikos A, Athienitis AK. The impact of shading design and control on building cooling and lighting demand. Sol Energy 2007;81 (3):369-82.

[47] Chungloo S, Limmeechokchai B. Application of passive cooling systems in the hot and humid climate: The case study of solar chimney and wetted roof in Thailand. Build and Environ 2007:42 (9):3341-51.

[48] Zhai XQ, Song ZP, Wang RZ. A review for the applications of solar chimneys in buildings. Renew and Sustainable Energy Rev 2011;15 (8):3757-67.

[49] Maerefat M, Haghighi AP. Natural cooling of stand-alone houses using solar chimney and evaporative cooling cavity. Renew Energy 2010;35 (9):2040-52.

[50] Raman P, Mande S, Kishore VVN. A passive solar system for thermal comfort conditioning of buildings in composite climates. Sol Energy 2001;70 (4):319-29.

[51] Dai YJ, Sumathy K, Wang RZ, Li YG. Enhancement of natural ventilation in a solar house with a solar chimney and a solid adsorption cooling cavity. Sol Energy 2003;74 (1):65-75.

[52] Miyazaki T, Akisawa A, Nikai I. The cooling performance of a building integrated evaporative cooling system driven by solar energy. Energy and Build 2011;43 (9):2211-18 .

[53] Givoni B. Indoor temperature reduction by passive cooling systems. Sol Energy 2011;85 (8):1692-726.

[54] Omer AM. Renewable building energy systems and passive human comfort solutions. Renew and Sustainable Energy Rev 2008;12:1562-87.

[55] Oropeza-Perez I, Ostergaard PA. Energy saving potential of utilizing natural ventilation under warm conditions - A case study of Mexico. Appl Energy 2014;130:20-32.

[56] Parys W, Breesch H, Hens $\mathrm{H}$, Saelens D. Feasibility assessment of passive cooling for office buildings in a temperate climate through uncertainty analysis. Build and Environ 2012;56:95-107.

[57] Hamdy IF, Fikry MA. Passive solar ventilation. Renew Energy 1998;14 (1-4):381-6.

[58] Li Y, Delsante A. Natural ventilation induced by combined wind and thermal forces. Build and Environ 2001;36 (1):59-71.

[59] Abreu Ml, Corvacho H, Dias RP. Passive systems for buildings using buoyancy-driven airflows. Recent Pat on Eng 2011;5 (1):23-31.

[60] Lishman B, Woods AW. On transitions in natural ventilation flow driven by changes in the wind. Build and Environ 2009;44 (4):666-73.

[61] Yuan J, Glicksman LR. Multiple steady states in combined buoyancy and wind driven natural ventilation: The conditions for multiple solutions and the critical point for initial conditions. Build and Environ 2008;43 (1):62-9.

[62] Wang $H$, Chen $Q$. A new empirical model for predicting single-sided, wind-driven natural ventilation in buildings. Energy and Build 2012;54:386-94. 
[63] Larsen TS, Heiselberg P. Single-sided natural ventilation driven by wind pressure and temperature difference. Energy and Build 2008;40 (6):1031-40.

[64] Ji L, Tan H, Kato S, Bu Z, Takahashi T. Wind tunnel investigation on influence of fluctuating wind direction on cross natural ventilation. Build and Environ 2011;46 (12):2490-9.

[65] Yang X, Zhong K, Zhu H, Kang Y. Experimental investigation on transient natural ventilation driven by thermal buoyancy. Build and Environ 2014;77:29-39.

[66] Khan N, Su Y, Riffat SB. A review on wind driven ventilation techniques. Energy and Build 2008;40 (8):1586-604.

[67] Gładyszewska-Fiedoruk K, Gajewski A. Effect of wind on stack ventilation performance. Energy and Build 2012;51:242-7.

[68] Hughes BR, Calautit JK, Ghani SA. The development of commercial wind towers for natural ventilation: A review. Appl Energy 2012;92:606-27.

[69] Saadatian O, Haw LC, Sopian K, Sulaiman MY. Review of windcatcher technologies. Renew and Sustainable Energy Rev 2012;16 (3):1477-95.

[70] Yang F, Qian F, Lau SSY. Urban form and density as indicators for summertime outdoor ventilation potential: A case study on high-rise housing in Shanghai. Build and Environ 2013;70:122-37.

[71] Lazzarin RM, Noro M. Energetic and economic savings of free cooling in different European climates. Int Jnl of Low-Carbon Technologies 2009;4:213-23.

[72] Alizadeh M, Sadrameli SM. Development of free cooling based ventilation technology for buildings: Thermal energy storage (TES) unit, performance enhancement techniques and design considerations - A review. Renew and Sustainable Energy Rev 2016;58:619-45.

[73] Quang TN, He C, Knibbs LD, De Dear R, Morawska L. Co-optimisation of indoor environmental quality and energy consumption within urban office buildings. Energy and Build 2014;85:225-34.

[74] Rodriguez-Ubinas E, Montero C, Porteros M, Vega S, Navarro I, Castillo-Cagigal M et al. Passive design strategies and performance of Net Energy Plus Houses. Energy and Build 2014;83:10-22.

[75] Artmann N, Manz H, Heiselberg P. Climatic potential for passive cooling of buildings by night-time ventilation in Europe. Appl Energy 2007; 84 (2): 187-201.

[76] Oropeza-Perez I, Ostergaard PA. Energy saving potential of utilizing natural ventilation under warm conditions - A case study of Mexico. Appl Energy 2014;130:20-32.

[77] Dovrtel K, Medved S. Weather-predicted control of building free cooling system. Appl Energy 2011;88 (9):3088-96.

[78] Inard C, Pfafferott J, Ghiaus C. Free-running temperature and potential for free cooling by ventilation: A case study. Energy and Build 2011;43 (10):2705-11.

[79] Bulut H, Aktacir MA. Determination of free cooling potential: A case study for İstanbul, Turkey. Appl Energy 2011;88 (3):680-9.

[80] Siriwardana J, Jayasekara S, Halgamuge SK. Potential of air-side economizers for data center cooling: A case study for key Australian cities. Appl Energy 2013;104:207-19.

[81] Zhang H, Shao S, Xu H, Zou H, Tian C. Free cooling of data centers: A review. Renew and Sustainable Energy Rev 2014;35:171-82. 
[82] ISO 7730:2005. Ergonomics of the thermal environment. Analytical determination and interpretation of thermal comfort using calculation of the PMV and PPD indices and local thermal comfort criteria.

[83] ASHRAE Standard 55: 2013. Thermal Environmental Conditions for Human Occupancy

[84] EN15252:2007. Indoor environmental input parameters for design and assessment of energy performance of buildings.

[85] Brager GS, de Dear RJ. Thermal adaptation in the built environment: a literature review. Energy and buildings, 1998;27 (1): 83-96.

[86] Dai J, Das D, Ohadi M, Pecht M. Reliability risk mitigation of free air cooling through prognostics and health management. Appl Energy 2013;111:104-12.

[87] Lee KP, Chen HL. Analysis of energy saving potential of air-side free cooling for data centers in worldwide climate zones. Energy and Build 2013;64:103-12.

[88] Vakiloroaya V, Samali B, Fakhar A, Pishghadam K. A review of different strategies for HVAC energy saving. Energy Convers and Manag 2014;77:738-54.

[89] Pacheco R, Ordóñez J, Martínez G. Energy efficient design of building: A review. Renew and Sustainable Energy Rev 2012;16 (6):3559-73.

[90] Camargo JR, Ebinuma CD, Silveira JL. Experimental performance of a direct evaporative cooler operating during summer in a Brazilian city. International J of Refrigeration 2005; 28 (7):1124-32.

[91] Velasco Gómez E, Rey Martínez FJ, Tejero González A. Experimental characterisation of the operation and comparative study of two semi-indirect evaporative systems. Appl Therm Eng 2010;30 (11-12):1447-54.

[92] Costelloe B, Finn D. Indirect evaporative cooling potential in air-water systems in temperate climates. Energy and Build 2003; 35 (6):573-91.

[93] Costelloe B, Finn D. Thermal effectiveness characteristics of low approach indirect evaporative cooling systems in buildings. Energy and Build 2007;39 (12):1235-43.

[94] Delfani S, Esmaeelian J, Pasdarshahri H, Karami M. Energy saving potential of an indirect evaporative cooler as a pre-cooling unit for mechanical cooling systems in Iran. Energy and Build 2010;42 (11);2169-76.

[95] Yang J, Chan KT, Wu X, Yu FW, Yang X. An analysis on the energy efficiency of air-cooled chillers with water mist system. Energy and Build 2012; 55:273-84.

[96] Ahmad A, Rehman S, Al-Hadhrami LM. Performance evaluation of an indirect evaporative cooler under controlled environmental conditions. Energy and Build 2013;62:278-85.

[97] Krüger E, González-Cruz E, Givoni B. Effectiveness of indirect evaporative cooling and thermal mass in a hot arid climate. Build and Environ 2010; 45 (6):1422-33.

[98] Smith ST, Hanby VI, Harpham C. A probabilistic analysis of the future potential of evaporative cooling systems in a temperate climate. Energy and Build 2011;43 (2-3):507-16.

[99] Duan Z, Zhan C, Zhang X, Mustafa M, Zhao X, Alimohammadisagvand B et al. Indirect evaporative cooling: Past, present and future potentials. Renew and Sustainable Energy Rev 2012;16 (9):6823-50.

[100] Wong NH, Chong AZM. Performance evaluation of misting fans in hot and humid climate. Build and Environ 2010;45 (12):2666-78.

[101] Heidarinejad G, Heidarinejad M, Delfani S, Esmaeelian J. Feasibility of using various kinds of cooling systems in a multi-climates country. Energy and Build 2008;40 (10);1946-53. 
[102] Baca MI, Tur MS, González NJ, Román AC. Evaporative Cooling efficiency according to climate conditions. Procedia Eng 2011; 21:283-90

[103] Kim MH, Kim JH, Choi AS, Jeong JW. Experimental study on the heat exchange effectiveness of a dry coil indirect evaporation cooler under various operating conditions. Energy 2011;36 (11):6479-89

[104] Tejero-González A, Andrés-Chicote M, Velasco-Gómez E, Rey-Martínez FJ. Influence of constructive parameters on the performance of two indirect evaporative cooler prototypes. Appl Therm Eng 2013; 51 (1-2):1017-25.

[105] Belarbi R, Allard F. Development of feasibility approaches for studying the behavior of passive cooling systems in buildings. Renew Energy 2001;22 (4):507-24.

[106] El-Refaie MF, Kaseb S. Speculation in the feasibility of evaporative cooling. Build and Environ 2009; 44 (4):826-38.

[107] Chapter 14 Climatic Design Information. In: ASHRAE Handbook Fundamentals. 2009.

[108] Bulut H, Büyükalaca O, Yilmaz T. New outdoor cooling design data for Turkey. Energy 2002;27 (10):923-46.

[109] Bulut H, Büyükalaca $O$. Simple model for the generation of daily global solar-radiation data in Turkey. Appl Energy 2007;84 (5):477-91

[110] Singh MK, Mahapatra S, Atreya SK. Bioclimatism and vernacular architecture of northeast India. Build and Environ 2009;44 (5):878-88.

[111] Rabah K. Development of energy-efficient passive solar building design in Nicosia Cyprus. Renew Energy 2005; 30 (6):937-56.

[112] Emmanuel R, Kumar B, Roderick Y, McEwan D. A universal climate-based energy and thermal expectation index: Initial development and tests. Energy and Build 2013; 58:208-18.

[113] Al-Azri N, Zurigatb YH, Al-Rawahia N. Selection and Assessment of Passive Cooling Techniques for Residential Buildings in Oman Using a Bioclimatic Approach. The $\mathrm{J}$ of Eng Res 2013;10 (2):52-68

[114] Zain-Ahmed A, Sayigh AAM, Surendran PN, Othman MY. The bioclimatic design approach to low-energy buildings in the Klang Valley, Malasya. Renew Energy 1998;15:437-40.

[115] Olgyay V. Design With Climate. Princeton University Press; 1963.

[116] Givoni B. Man, Climate and Architecture. 2nd ed. London: Applied Science Publishers;1976.

[117] Lomas KJ, Fiala D, Cook MJ, Cropper PC. Building bioclimatic charts for non-domestic buildings and passive downdraught evaporative cooling. Build and Environ 2004;39 (6):661-79.

[118] Guan L, Bennett M, Bell J. Development of a climate assessment tool for hybrid air conditioner. Build and Environ 2014;82:371-80

[119] Mahmoud AHA. An analysis of bioclimatic zones and implications for design of outdoor built environments in Egypt. Build and Environ 2011;46 (3);605-20.

[120] Lam JC, Yang L, Liu J. Development of passive design zones in China using bioclimatic approach. Energy Convers and Manag 2006; 47 (6):746-62.

[121] Rakoto-Joseph O, Garde F, David M, Adelard L, Randriamanantany ZA. Development of climatic zones and passive solar design in Madagascar. Energy Convers and Manag 2009;50 (4):1004-10. 
[122] Bodach S, Lang W, Hamhaber J. Climate responsive building design strategies of vernacular architecture in Nepal. Energy and Build 2014; 81:227-42.

[123] Sad De Assis E, Barros Frota A. Urban bioclimatic design strategies for a tropical city. Atmospheric Environ 1999; 33 (24-25):4135-42.

[124] UCLA, Climate consultant 5 http://www.energy-design-tools.aud.ucla.edu/ (last access 1606-2015).

[125] Rupp RF, Ghisi E. What is the most adequate method to assess thermal comfort in hybrid commercial buildings located in hot-humid summer climate? Renew and Sustainable Energy Rev 2014;29:449-62. 

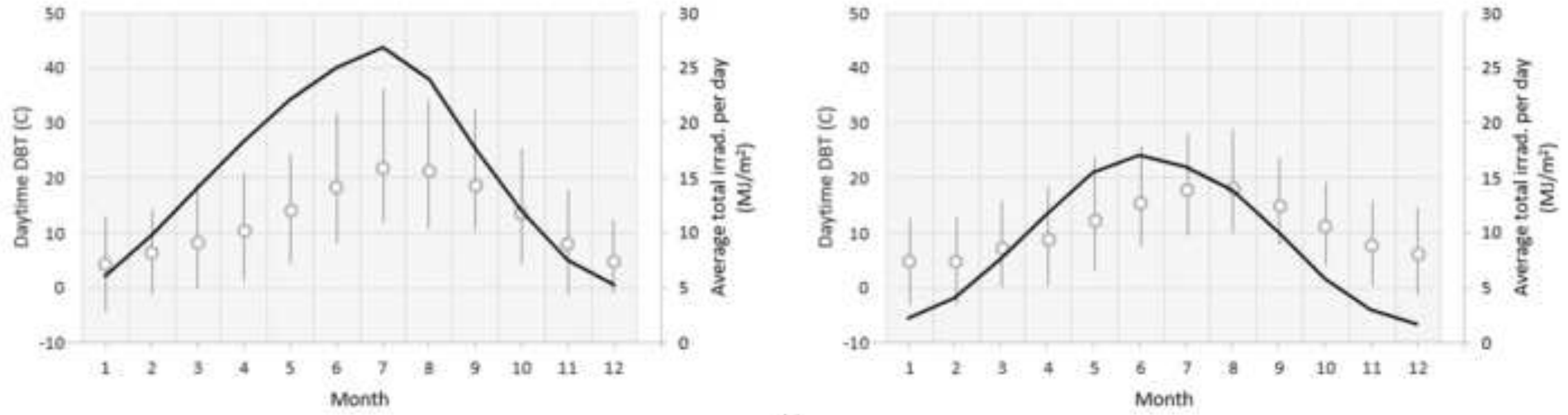

a)

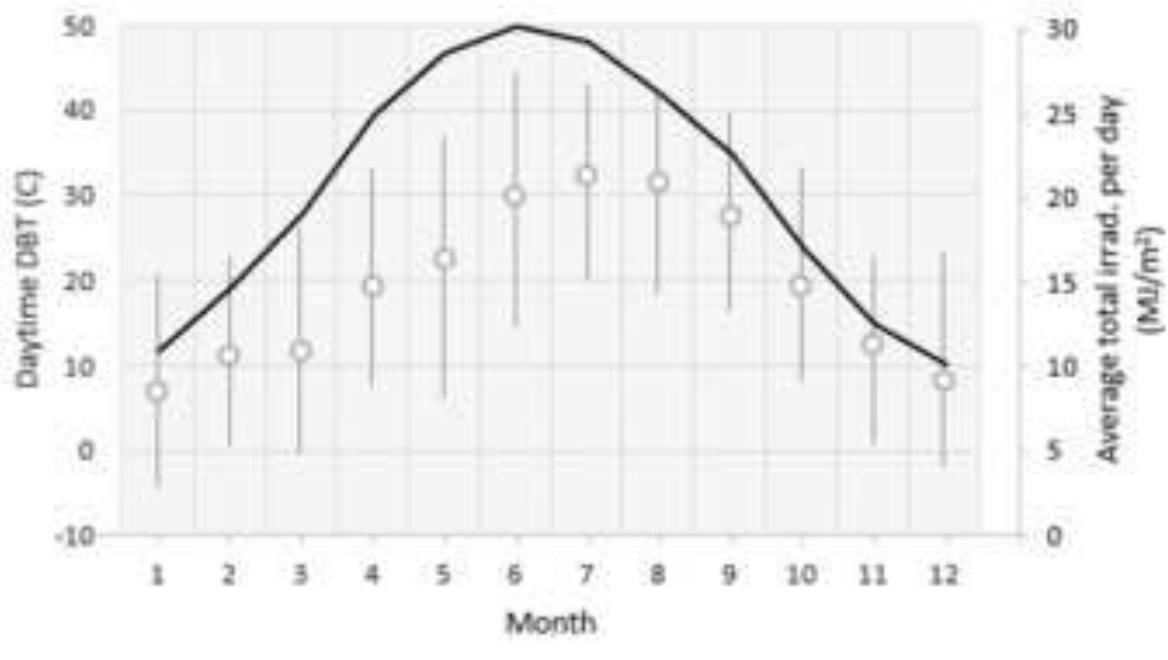

b)

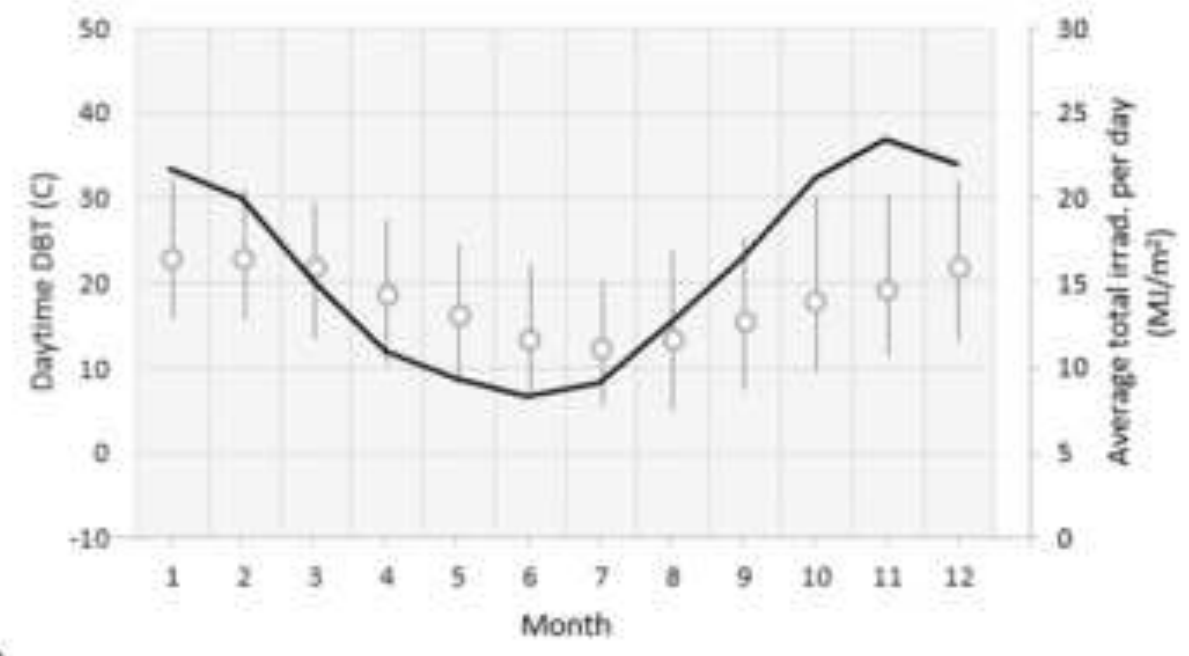

d) 
a)
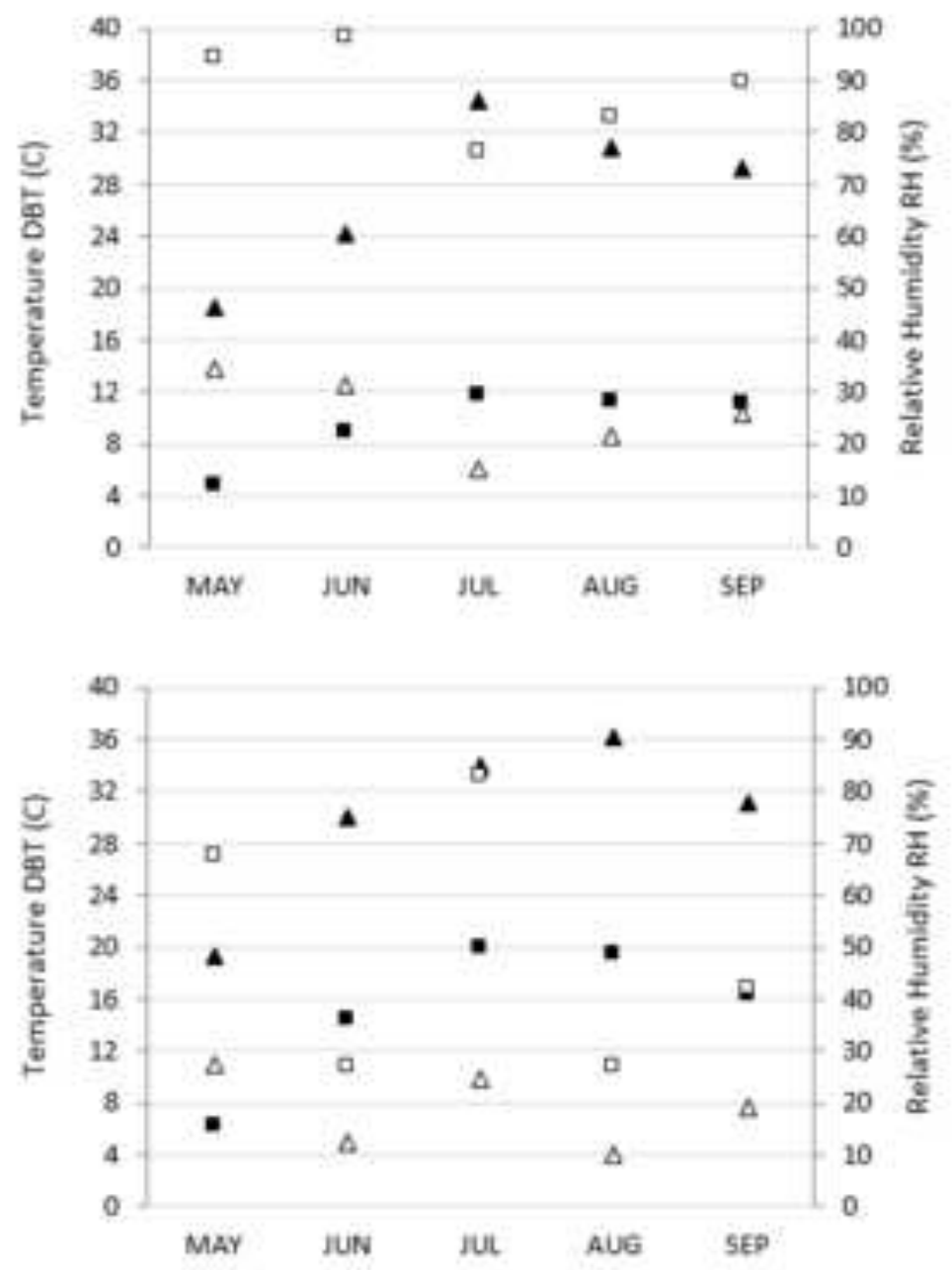

b)

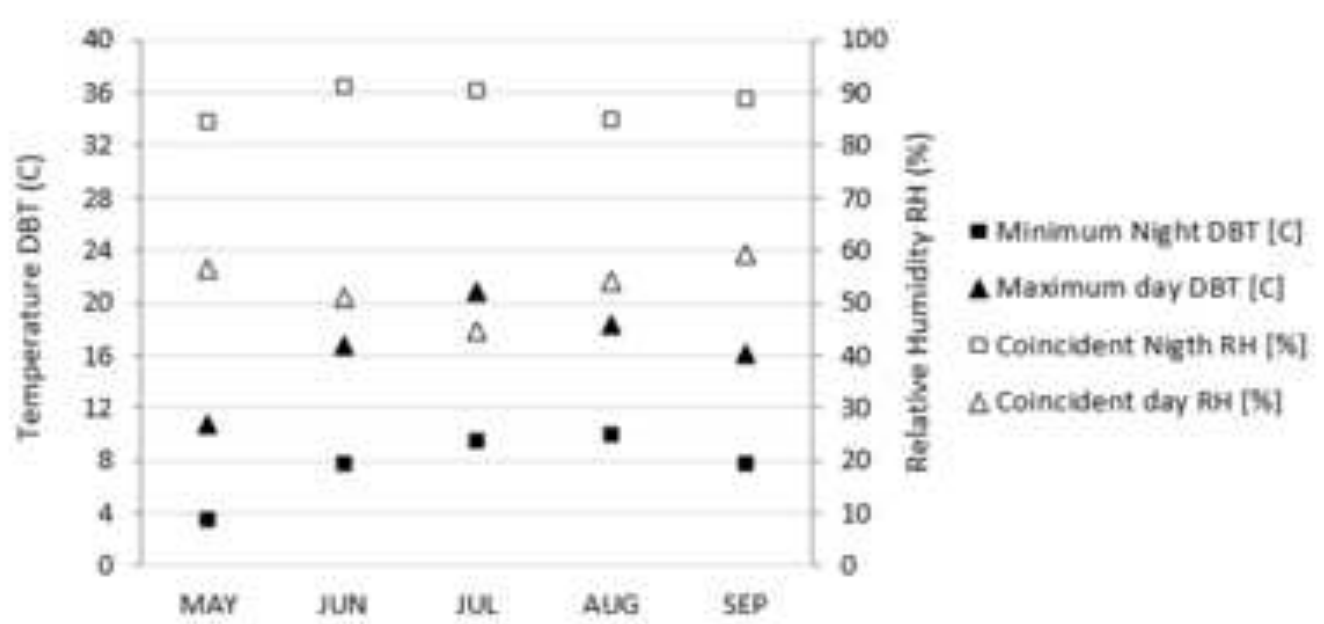

.

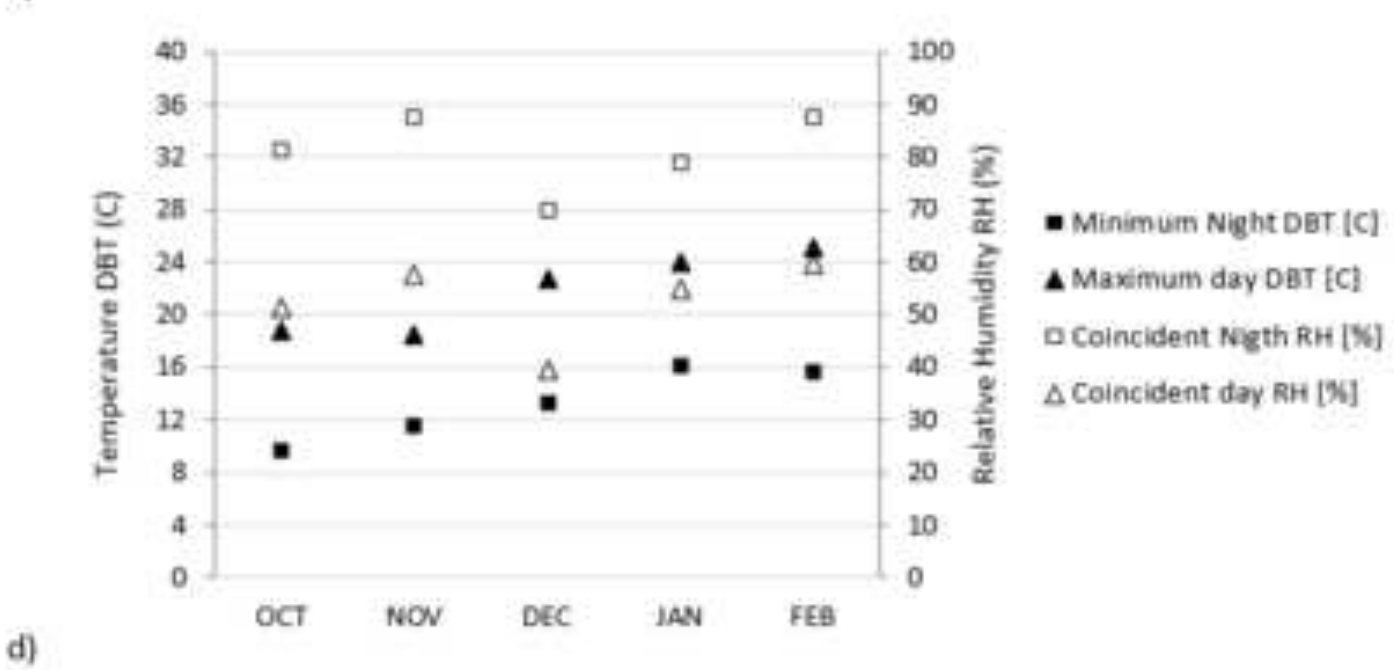

d) 
Wet-bulb depression (WBD)
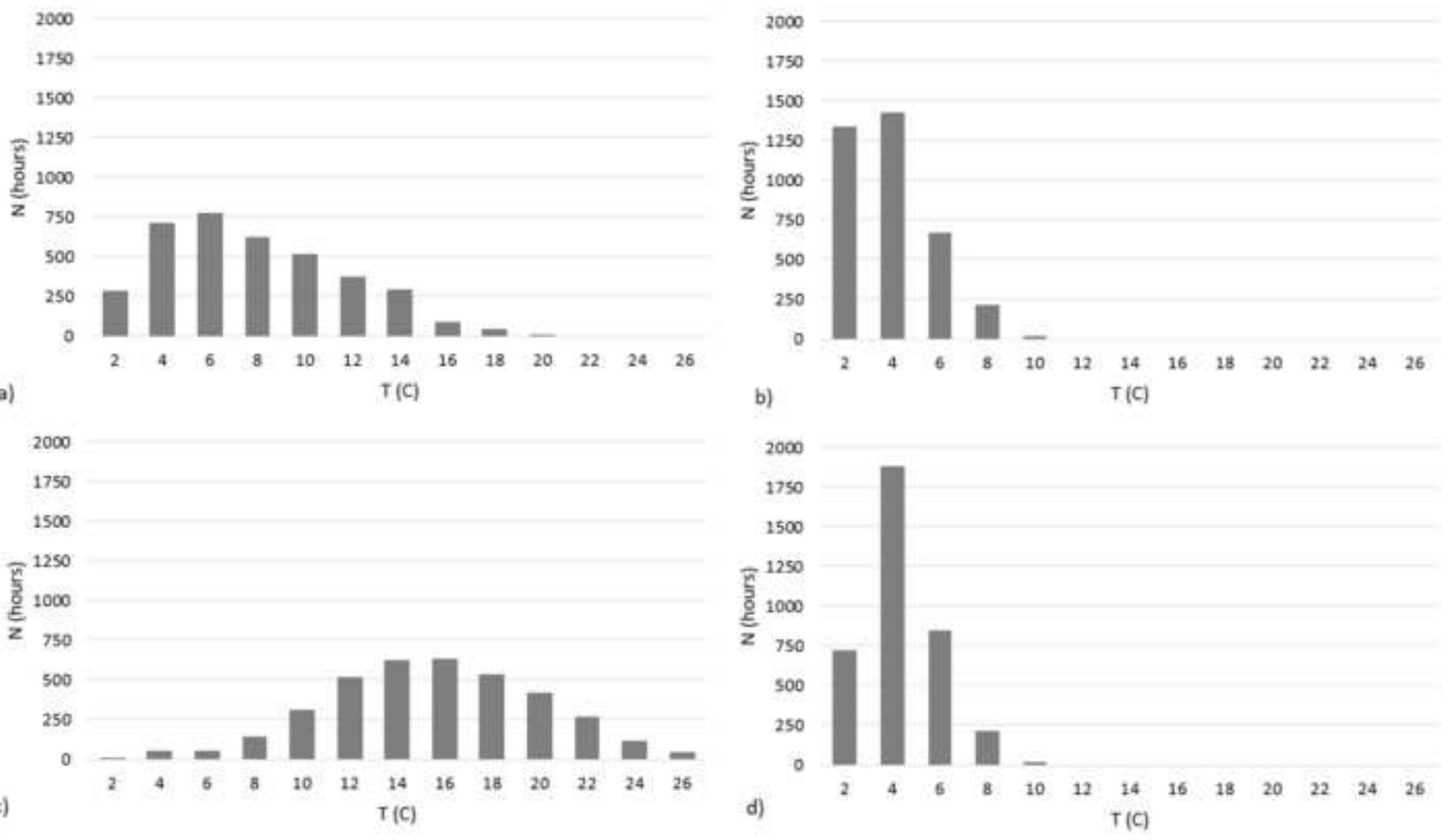
Figure

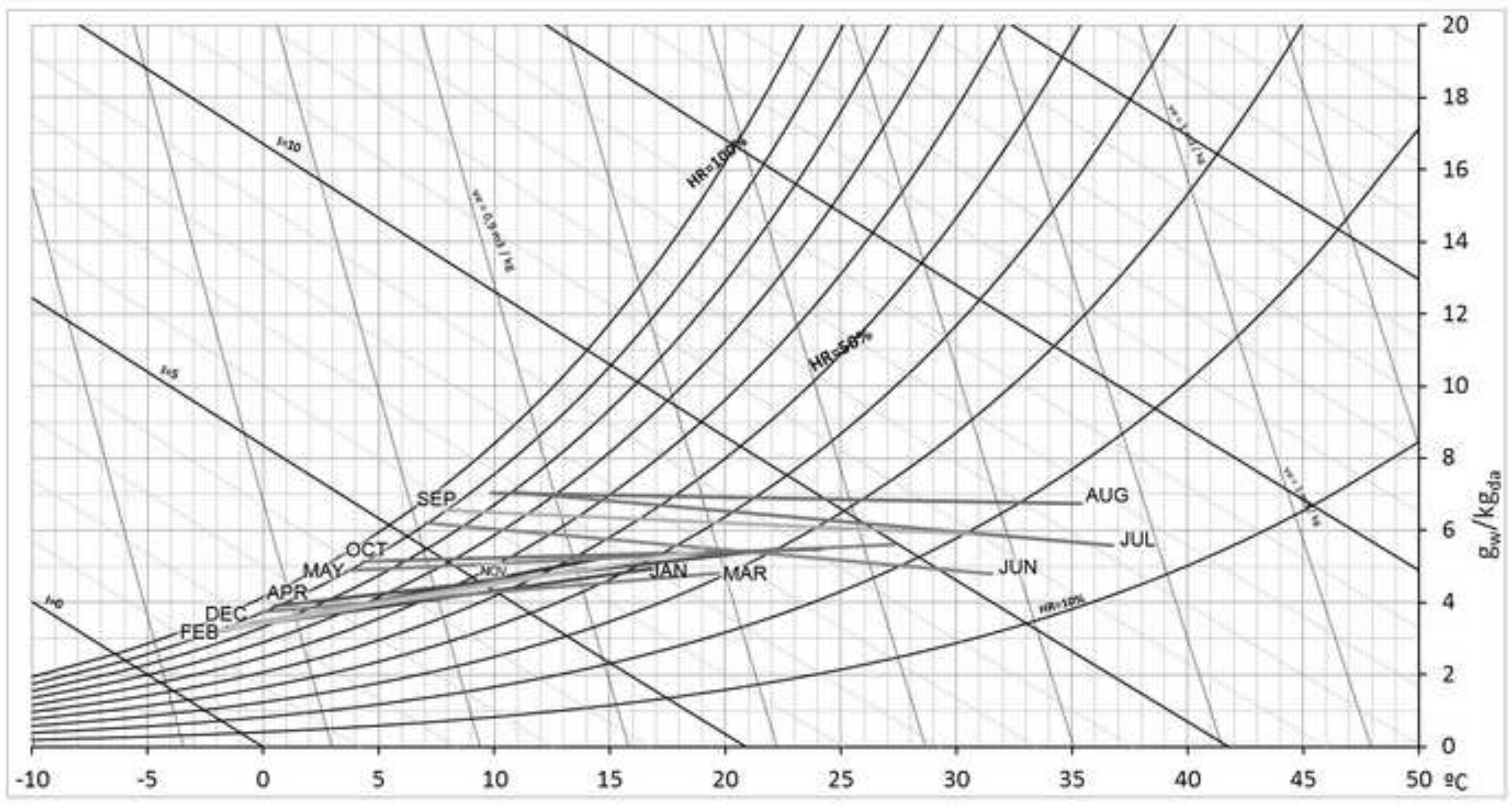




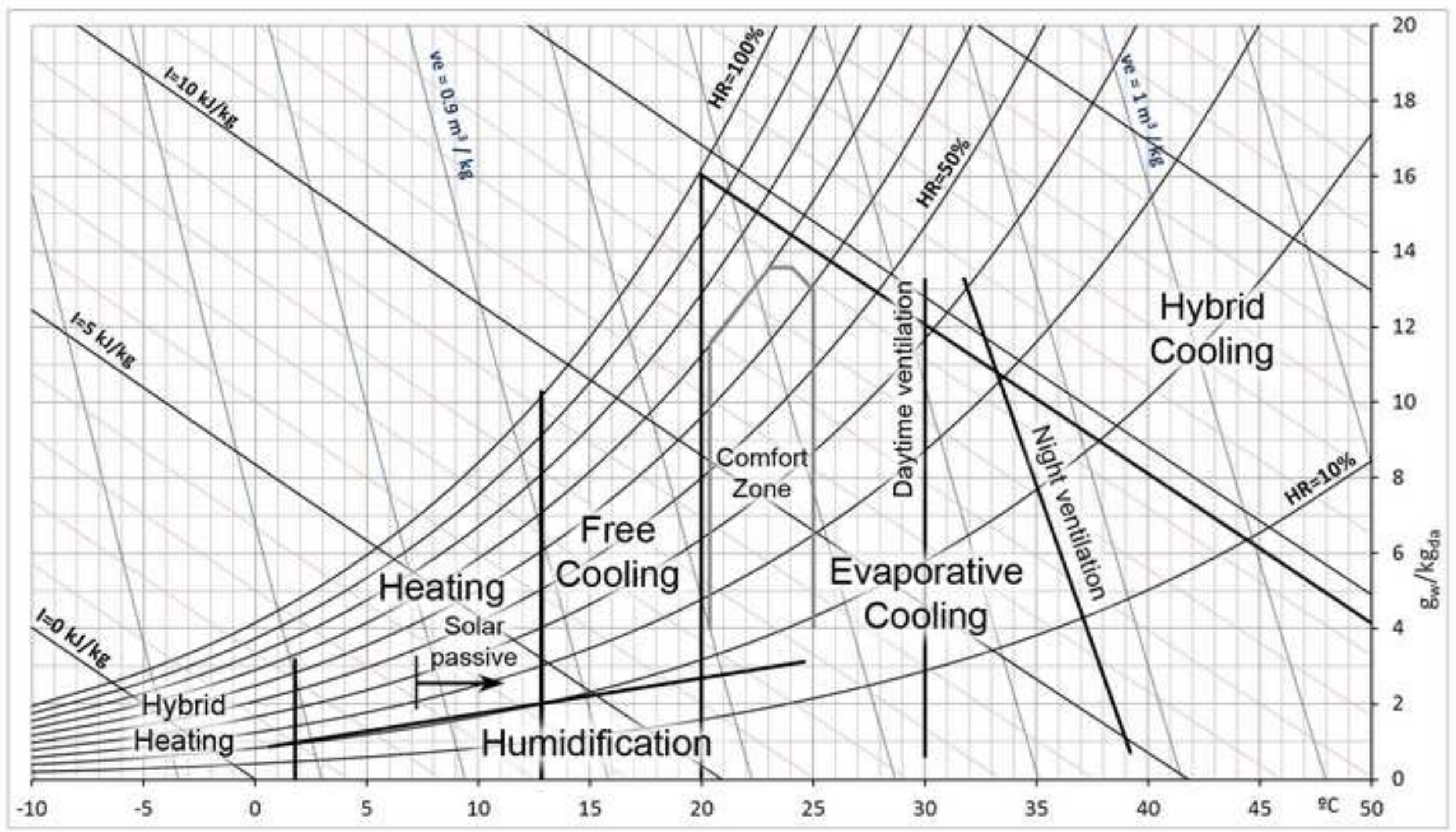


Table 1: Review of climate considerations for interesting applications of solar passive strategies.

\begin{tabular}{|c|c|c|c|}
\hline $\begin{array}{l}\text { PASSIVE and LOW } \\
\text { ENERGY } \\
\text { STRATEGIES for } \\
\text { thermal comfort }\end{array}$ & $\begin{array}{l}\text { Climate Key } \\
\text { Parameters }\end{array}$ & $\begin{array}{l}\text { Optimal climate } \\
\text { conditions }\end{array}$ & Reference \\
\hline $\begin{array}{l}\text { Solar passive: } \\
\text { Trombe wall }\end{array}$ & \multirow[t]{2}{*}{$\begin{array}{l}\text { - Solar irradiation } \\
\text { - Outdoor } \mathrm{DBT}^{*}\end{array}$} & Cold climates & \multirow[b]{2}{*}[42,41,44]{} \\
\hline $\begin{array}{l}\text { Trombe wall } \\
\text { +shading } \\
\text { +ventilation and } \\
\text { insulation options }\end{array}$ & & $\begin{array}{l}\text { Acceptable for mild } \\
\text { and hot climates }\end{array}$ & \\
\hline $\begin{array}{l}\text { Solar passive: } \\
\text { Solar chimney }\end{array}$ & $\begin{array}{l}\text { - } \text { Solar irradiation** } \\
\text { - } \text { Outdoor } \mathrm{DBT}^{\star} \\
\text { - } \text { Wind direction }{ }^{* *} \text {. }\end{array}$ & $\begin{array}{l}\text { High solar irradiation } \\
\text { and low wind speed }\end{array}$ & {$[48,51]$} \\
\hline $\begin{array}{l}\text { Solar chimney } \\
\text { +insulation options }\end{array}$ & $\begin{array}{l}\text { - Solar irradiation } \\
\text { - Outdoor } \mathrm{DBT}^{*} \\
\text { - Wind direction. }\end{array}$ & $\begin{array}{l}\text { Acceptable for hot } \\
\text { climates }\end{array}$ & [43] \\
\hline $\begin{array}{l}\text { Solar chimney } \\
\text { +evaporative cooling }\end{array}$ & $\begin{array}{ll}\text { - } & \text { Solar irradiation } \\
\text { - } & \text { Outdoor DBT* } \\
\text { - } & \text { Wind direction. } \\
\text { - } & \text { Relative Humidity }\end{array}$ & $\begin{array}{l}\text { Acceptable for lower } \\
\text { solar irradiation and } \\
\text { high DBT; } \mathrm{RH}<50 \%\end{array}$ & {$[49,52,47]$} \\
\hline
\end{tabular}

${ }^{*}$ Requires further information about *indoor conditions or **the particular location. 
Table 2: Review of climate considerations for interesting application of ventilation strategies.

\begin{tabular}{|c|c|c|c|}
\hline $\begin{array}{l}\text { PASSIVE and LOW } \\
\text { ENERGY } \\
\text { STRATEGIES for } \\
\text { thermal comfort }\end{array}$ & $\begin{array}{l}\text { Climate Key } \\
\text { Parameters }\end{array}$ & $\begin{array}{l}\text { Optimal climate } \\
\text { conditions }\end{array}$ & Reference \\
\hline $\begin{array}{l}\text { Ventilation } \\
\text { Natural (daytime) } \\
\text { ventilation }\end{array}$ & $\begin{array}{ll}\text { - } & \text { Wind velocity }{ }^{* *} \\
\text { - } & \text { Wind direction** } \\
\text { - } & \text { Outdoor } \mathrm{DBT}^{*} \\
\text { - } & \text { Relative Humidity }\end{array}$ & $\begin{array}{l}\text { - } \text { Prevailing favorable } \\
\text { wind directions } \\
\text { - High wind speed } \\
\text { - Outdoor DBT slightly } \\
\text { over comfort }\end{array}$ & $\begin{array}{c}{[53,65,57,60,} \\
66]\end{array}$ \\
\hline -Single-sided & $\begin{array}{ll}\text { - } & \text { Wind velocity } \\
\text { - } & \text { Wind direction } \\
\text { - } & \text { Outdoor } \mathrm{DBT}^{\star}\end{array}$ & & {$[62,63]$} \\
\hline -Cross ventilation & - Wind direction & & [64] \\
\hline -Stack ventilation. & $\begin{array}{ll}\text { - } & \text { Outdoor } \mathrm{DBT}^{*} \\
\text { - } & \text { Wind velocity } \\
\text { - } & \text { Wind direction }\end{array}$ & & {$[67,68]$} \\
\hline -Wind towers. & - Wind direction** & & [69] \\
\hline
\end{tabular}

${ }^{*}$ Requires further information about *indoor conditions or ${ }^{* *}$ the particular location. 
Table 3: Review of climate considerations for interesting application of free cooling.

\begin{tabular}{|c|c|c|c|}
\hline $\begin{array}{l}\text { PASSIVE and LOW } \\
\text { ENERGY } \\
\text { STRATEGIES for } \\
\text { thermal comfort }\end{array}$ & $\begin{array}{c}\text { Climate Interesting } \\
\text { Parameters }\end{array}$ & $\begin{array}{l}\text { Optimal climate } \\
\text { conditions }\end{array}$ & Reference \\
\hline $\begin{array}{l}\text { Free-cooling } \\
\text { Night ventilation }\end{array}$ & - $\quad$ Min. Night $\mathrm{DBT}^{*}$ & $\begin{array}{l}\text { High daytime DBT and } \\
\text { low nighttime DBT }\end{array}$ & {$[53,75]$} \\
\hline $\begin{array}{l}\text { Free-cooling } \\
\text { Daytime free-cooling }\end{array}$ & $\begin{array}{l}\text { - } \\
\text { - Outdoor DBT } \\
\text { - Outdoor DPT } \\
\text { Outdoor RH }\end{array}$ & $\begin{array}{l}\text { Outdoor DBT below } \\
\text { comfort. } \\
\text { Outdoor DBT<15C } \\
\text { Inter-seasonal periods } \\
\text { mixed-humid, warm- } \\
\text { marine, and mixed- } \\
\text { marine climates }\end{array}$ & $\begin{array}{c}{[9,77,78,79,} \\
80,81]\end{array}$ \\
\hline
\end{tabular}

${ }^{*}$ Requires further information about *indoor conditions or **the particular location. 
Table 4.: Free cooling potential (number of hours of applicability) for different base temperatures, working period and relative humidity restrictions for the four climates studied.

VALLADOLID

\begin{tabular}{|ccccccc|}
\hline & \multicolumn{2}{c}{$(24 \mathrm{~h} /$ day $)$} & \multicolumn{2}{c}{$(8$ a.m. -8 p.m. $)$} & \multicolumn{2}{c|}{$\begin{array}{c}(24 \mathrm{~h} / \text { day }) \\
(\mathrm{RH}<60 \%)\end{array}$} \\
\hline T_base & Whole & Cooling & Whole & Cooling & Whole & Cooling \\
$(\mathrm{C})$ & year & season & year & season & year & season \\
\hline 24 & 8032 & 2954 & 4022 & 1276 & 2985 & 1811 \\
21 & 7482 & 2451 & 3544 & 845 & 2435 & 1308 \\
18 & 6713 & 1780 & 3064 & 461 & 1706 & 677 \\
15 & 5647 & 1000 & 2532 & 193 & 922 & 149 \\
\hline
\end{tabular}

LONDON

\begin{tabular}{|ccccccc|}
\hline & \multicolumn{2}{c}{$(24 \mathrm{~h} /$ day $)$} & \multicolumn{2}{c}{$(8$ a.m. -8 p.m. $)$} & \multicolumn{2}{c|}{$\begin{array}{c}(24 \mathrm{~h} / \text { day }) \\
(\mathrm{RH}<60 \%)\end{array}$} \\
\hline T_base & Whole & Cooling & Whole & Cooling & Whole & Cooling \\
$(\mathrm{C})$ & year & season & year & season & year & season \\
\hline 24 & 8659 & 3571 & 4648 & 1892 & 783 & 517 \\
21 & 8367 & 3279 & 4399 & 1643 & 639 & 373 \\
18 & 7676 & 2598 & 3873 & 1127 & 423 & 164 \\
15 & 6627 & 1656 & 3202 & 559 & 252 & 43 \\
\hline
\end{tabular}

LAS VEGAS

\begin{tabular}{|ccccccc|}
\hline & \multicolumn{2}{c}{$(24 \mathrm{~h} /$ day $)$} & \multicolumn{2}{c|}{$($ (8 a.m. -8 p.m. $)$} & \multicolumn{2}{c|}{ (24 h/day) \& $(\mathrm{RH}<$} \\
\hline T_base & Whole & Cooling & Whole & Cooling & Whole & Cooling \\
$(\mathrm{C})$ & year & season & year & season & year & season \\
\hline 24 & 5640 & 886 & 2618 & 184 & 4960 & 826 \\
21 & 4919 & 470 & 2282 & 94 & 4254 & 425 \\
18 & 4111 & 205 & 1825 & 57 & 3471 & 185 \\
15 & 3346 & 93 & 1333 & 25 & 2720 & 79 \\
\hline
\end{tabular}

SIDNEY

\begin{tabular}{|ccccccc|}
\hline & \multicolumn{2}{c}{$(24 \mathrm{~h} /$ day $)$} & \multicolumn{2}{c}{$($ (8 a.m. -8 p.m. $)$} & \multicolumn{2}{c|}{ (24 h/day) \& $(\mathrm{RH}<$} \\
\hline T_base & Whole & Cooling & Whole & Cooling & Whole & Cooling \\
$(\mathrm{C})$ & year & season & year & season & year & season \\
\hline 24 & 7775 & 2851 & 3880 & 1301 & 1335 & 378 \\
21 & 6181 & 1805 & 2851 & 667 & 960 & 176 \\
18 & 4391 & 841 & 1840 & 206 & 574 & 42 \\
15 & 2632 & 246 & 924 & 29 & 211 & 0 \\
\hline
\end{tabular}


Table 5: Review of climate considerations for interesting application of evaporative cooling.

\begin{tabular}{|c|c|c|c|}
\hline $\begin{array}{l}\text { PASSIVE and LOW } \\
\text { ENERGY } \\
\text { STRATEGIES for } \\
\text { thermal comfort }\end{array}$ & $\begin{array}{c}\text { Climate Interesting } \\
\text { Parameters }\end{array}$ & $\begin{array}{l}\text { Optimal climate } \\
\text { conditions }\end{array}$ & Reference \\
\hline $\begin{array}{l}\text { Evaporative cooling } \\
\text { DEC }\end{array}$ & $\begin{array}{ll}\text { - } & \text { Outdoor DBT } \\
\text { - } & \text { Outdoor RH (WBT) } \\
\text { - } & \text { Outdoor-indoor } \\
& \text { Enthalpy difference }\end{array}$ & $\begin{array}{l}\text { Hot and dry climates } \\
\text { Humid climates } \\
\text { (limited) } \\
\text { Cfb, Csb, Csa climates }\end{array}$ & $\begin{array}{c}{[90,91]} \\
{[100]} \\
{[71]}\end{array}$ \\
\hline $\begin{array}{l}\text { Evaporative cooling } \\
\text { IEC }\end{array}$ & $\begin{array}{l}\text { - Outdoor DBT } \\
\text { - Indoor enthalpy }\end{array}$ & $\begin{array}{l}\text { Hot and dry climates } \\
\text { Temperate climates } \\
\text { Cfb, Csb, Csa climates }\end{array}$ & $\begin{array}{c}{[97,99]} \\
{[92,93,98]} \\
{[71]}\end{array}$ \\
\hline $\begin{array}{l}\text { Evaporative cooling } \\
D E C+I E C\end{array}$ & - Outdoor DBT & $\begin{array}{l}\text { Hot and dry, or } \\
\text { temperate and more } \\
\text { humid climates }\end{array}$ & {$[101,102]$} \\
\hline $\begin{array}{l}\text { Evaporative cooling } \\
I E C+\text { heat recovery }\end{array}$ & $(\text { None directly })^{*}$ & Humid climates & {$[103,104]$} \\
\hline
\end{tabular}

${ }^{*}$ Requires further information about *indoor conditions or ${ }^{* *}$ the particular location. 